NBER WORKING PAPER SERIES

\title{
ADVISORS AND ASSET PRICES: A MODEL OF THE ORIGINS OF BUBBLES
}

\author{
Harrison Hong \\ Jose A. Scheinkman \\ Wei Xiong \\ Working Paper 13504 \\ http://www.nber.org/papers/w13504
}

\author{
NATIONAL BUREAU OF ECONOMIC RESEARCH \\ 1050 Massachusetts Avenue \\ Cambridge, MA 02138 \\ October 2007
}

\begin{abstract}
We thank Kerry Back, Henry Cao, John Eatwell, Simon Gervais, Ming Huang, Robert Jarrow, Maureen O'Hara, Jacob Sagi, Robert Shiller, Sheridan Titman, Pietro Veronesi, and seminar participants at the Bank of England, Cornell University, St. Louis Federal Reserve Bank, 2006 American Finance Association Annual Meeting in Philadelphia, 12th Mitsui Life Symposium at University of Michigan, Cambridge-Princeton Conference on Finance, CEPR/Pompeu Fabra Bubble Conference, Duke-UNC Asset Pricing Conference, Financial Intermediation Research Society Conference in Shanghai and NBER Behavioral Finance Conference for helpful comments. We thank the National Science Foundation for financial support under grants SES0350770 and SES0718407. The views expressed herein are those of the author(s) and do not necessarily reflect the views of the National Bureau of Economic Research.
\end{abstract}

(C) 2007 by Harrison Hong, Jose A. Scheinkman, and Wei Xiong. All rights reserved. Short sections of text, not to exceed two paragraphs, may be quoted without explicit permission provided that full credit, including $\odot$ notice, is given to the source. 
Advisors and Asset Prices: A Model of the Origins of Bubbles

Harrison Hong, Jose A. Scheinkman, and Wei Xiong

NBER Working Paper No. 13504

October 2007

JEL No. G1,G14,G2

\begin{abstract}
$\underline{\text { ABSTRACT }}$
We develop a model of asset price bubbles based on the communication process between advisors and investors. Advisors are well-intentioned and want to maximize the welfare of their advisees (like a parent treats a child). But only some advisors understand the new technology (the tech-savvies); others do not and can only make a downward-biased recommendation (the old-fogies). While smart investors recognize the heterogeneity in advisors, naive ones mistakenly take whatever is said at face value. Tech-savvies inflate their forecasts to signal that they are not old-fogies, since more accurate information about their type improves the welfare of investors in the future. A bubble arises for a wide range of parameters, and its size is maximized when there is a mix of smart and naive investors in the economy. Our model suggests an alternative source for stock over-valuation in addition to investor overreaction to news and sell-side bias.
\end{abstract}

\author{
Harrison Hong \\ Berndheim Center for Finance \\ Princeton University \\ 26 Prospect Avenue \\ Princeton, NJ 08540 \\ hhong@Princeton.EDU
}

Jose A. Scheinkman

Department of Economics

Princeton University

Princeton, NJ 08544-1021

and NBER

joses@princeton.edu

\author{
Wei Xiong \\ Princeton University \\ Department of Economics \\ Bendheim Center for Finance \\ Princeton, NJ 08450 \\ and NBER \\ wxiong@princeton.edu
}


"To be against what is new is not to be modern. Not to be modern is to write yourself out of the scene. Not to be in the scene is to be nowhere." Tom Wolfe, The Painted Word

\section{Introduction}

What are the origins of speculative asset price bubbles? This question remains unanswered despite a large and growing literature on speculative trading and asset price bubbles in economics. Motivated in part by the behavior of internet stocks during the late nineties, a surge in new research has arrived at two conclusions. The first is that differences of opinion among investors and short sales constraints are sufficient to generate a price bubble. ${ }^{1}$ The second is that once a bubble begins, it is difficult for smart money to eliminate the mispricing (i.e. there are limits of arbitrage). ${ }^{2}$ All these studies take as given that investors disagree about asset values. But where does this divergence of opinion come from?

In this paper, we develop a model of the origins of bubbles. Two sets of stylized facts motivate our analysis. The first is that asset price bubbles tend to occur during periods of excitement about new technologies. ${ }^{3}$ In the U.S., speculative episodes have coincided with the following major technological breakthroughs: (1) railroads, (2) electricity, (3) automobiles, (4) radio, (5) micro-electronics, (6) personal computers, (7) biotechnology, and most recently (8) the Internet. ${ }^{4}$ The second is that in the aftermath of the Internet bubble, the media and regulators placed much of the blame on biased advisors for manipulating the expectations of naive investors. While not directly related to the Internet experience, indirect evidence from academic research in support of this view held by the media and regulators include: (1) analyst incentives to generate biased, optimistic forecasts; (2) naive individual investors who do not recognize that these biased recommendations are motivated by incentives to sell

\footnotetext{
${ }^{1}$ See, e.g., Miller (1977), Harrison and Kreps (1978), Chen, Hong and Stein (2002), and Scheinkman and Xiong (2003). Extensive empirical work confirming this premise include Diether, Malloy and Scherbina (2002), Lamont and Thaler (2003), and Ofek and Richardson (2003). This literature stands in contrast to the rational bubble literature (see, e.g., Blanchard and Watson, 1982) in which these two ingredients are not crucial in an infinite horizon setting. However, Allen, Morris, and Postlewaite (1993) show that these two ingredients emerge as relevant again to generate a rational bubble in a finite horizon setting.

${ }^{2}$ See, e.g., Shleifer and Vishny (1997), Abreu and Brunnermeier (2003).

${ }^{3}$ See, e.g., Malkiel (2003), Nairn (2002), Shiller (2000).

${ }^{4}$ See DeMarzo, Kaniel and Kremer (2006) and Pastor and Veronesi (2006) for rational explanations of high stock prices for new technologies.
} 
stocks; and (3) analysts' optimistic forecasts have an impact on prices. ${ }^{5}$

We focus on the role of advisors and their communication process with investors in generating divergence of opinion and asset price bubbles. Building on the existing literature, we assume that there are two types of investors, smart and naive, who are short sales constrained. While smart investors recognize the heterogeneity in advisors, naive ones take whatever recommendations they receive at face value. Importantly, all advisors are well-intentioned in that they care about the welfare of their advisees and want to honestly disclose their signals to investors. We also assume that at times of technological innovation, only some advisors understand the new technology (the tech-savvies); others do not and can only make a downward-biased recommendation (the old-fogies). We also consider an alternative assumption in which the old-fogies are replaced by dreamers who only issue upward-biased recommendations. The divergence of opinion and price bias results do not depend on this assumption but the old-fogey assumption is more theoretically interesting and there is evidence that it is relevant at a minimum for the recent internet experience. ${ }^{6}$

A key contribution of our model is that it serves as a warning that even if a stock appears over-valued, it may not be due to investors overreacting to news nor to sell-side bias. We are not disclaiming the role of sell-side bias in the dot-com bubble - only that such bias is not needed to generate asset price bubbles. Indeed, it is not clear that such bias can explain bubbles that have occurred during earlier periods. We observe that during the dot-com period, even so-called objective research firms with no investment-banking business, such as Sanford and Bernstein, issued recommendations every bit as optimistic as investment banks

\footnotetext{
${ }^{5}$ See, e.g., Lin and McNichols (1998), Hong and Kubik (2003) for evidence on analyst incentives, Malmendier and Shantikumar (2004) for evidence on investor reaction to recommendations and Michaely and Womack (1999) for evidence on price impact.

${ }^{6}$ Throughout The Painted Word, from which our epigraph is drawn, Tom Wolfe describes the loss of credibility suffered by art critics who were perceived as not "getting" the new pop art movement of the late fifties. There is ample anecdotal evidence suggesting that advisors during the dot-com bubble faced similar concerns. For instance, Stanley Druckenmiller, a self-confessed old economy dinosaur and value investor, reversed course during the Internet boom period and declared that he understood the Internet after a meeting with guru Andrew Grove (see Pacelle, 2000). Famous examples of old-fogies include Jonathan Cohen, a sell-side analyst covering Internet stocks for Merrill Lynch who was fired for his skeptical reports about the Internet. In contrast, Mary Meeker, a vocal proponent of the Internet revolution, not only prospered during the Internet era but continues to be an influential voice in technology even after the bursting of the bubble. Finally, there also is evidence that young mutual fund managers were more aggressively holding technology stocks during the dot-com bubble as compared to their older counterparts (see, e.g. Greenwood and Nagel, 2006).
} 
(see, e.g., Cowen, Groysberg, and Healy, 2003). ${ }^{7}$ This suggests that there must exist other causes of upward biased forecasts by advisors aside from the sell-side incentives of analysts. Moreover, we think of our model as applying more broadly to other advisors such as buy-side analysts who are likely to be a more important part of the market. In short, our paper is an exploration of an alternative and potentially more theoretically interesting mechanism for generating divergence of opinion as opposed to simply assuming investors overreact to news or are overly exuberant.

More specifically, we consider an economy with a single asset, which we call the new technology stock. There are three dates, 0, 1 and 2. At date 0 , advisors are randomly matched with investors (the advisees). Advisors also observe the terminal payoff (which is realized at date 2) and can send signals about this payoff to their advisees at date 0 . A techsavvy can send whatever signal he wants, while an old-fogey, who does not understand the new technology, is limited to a downward-biased signal. The investor type is unknown to the advisor, and the advisor type is unknown to the investor. The advisor-investor relationship is similar to that of a parent and teenaged child, in which the smart teenager is not sure whether dad is cool, and the cool dad tries to impress his teenaged child because he wants his child to heed his advice in the future.

At date 1, these advisors are randomly matched with a new set of investors. These investors can invest in a separate risky project requiring an initial fixed cost. Advisors again receive information about this risky project, which pays off at date 2 . Once again, a tech-savvy can send whatever signal he wants, while an old-fogey is restricted to a downwardbiased signal. Each investor has access to the track record of his advisor, namely the signal (or recommendation) that was sent by the latter at date 0 . A smart investor can use this information to update his belief about his advisor's type.

To put this simple model into some context, think of the advisor at date 0 as a sell-side analyst covering technology stocks, but (counterfactually) with only good intentions. Date 1 represents the future career opportunities of this analyst; for example, sell-side analysts typically become advisors to hedge funds or corporations later in their careers. Importantly,

\footnotetext{
${ }^{7}$ Moreover, Grosyberg et al. (2005) find that buy-side analysts (those working at mutual funds without brokerage or investment banking relationships) issue even more optimistic forecasts than their sell-side counterparts.
} 
what the advisor says at date 0 can be used for or against him at date 1 . The updating of a smart investor's belief about his advisor's type is a key driver of our model.

We first consider the equilibrium at date 1 . Because of uncertainty about advisor type, smart investors may end up making investments when they should not, since they are not sure whether a negative signal (i.e., a signal value less than the fixed cost of investing) is truly negative or if it just came from an old-fogey. We solve for a Bayesian-Nash equilibrium in the reporting strategies of the advisors and the investment policies of the advisees. In this equilibrium, tech-savvy advisors bias their signals downward over the set of states in which it is not efficient for the advisee to invest. By downwardly biasing their signals over these states, the tech-savvy advisors lead the smart advisees to conclude that a certain set of negative signals cannot be generated by tech-savvy advisors. This signaling enables smart investors to avoid at least some inefficient investments. However, it also imposes a dishonesty cost upon the tech-savvy advisor, and this dishonesty cost is incurred per advisee.

As a result, the tech-savvy advisor has an incentive to establish a better reputation at date 0 through his recommendation about the technology stock, since smart investors subsequently will use his date 0 recommendation to update their beliefs on his type. The stronger his reputation among smart investors becomes at date 1, the more easily he can avoid dishonesty costs in inducing his advisees to make efficient investments in that period. This reputational incentive leads the tech-savvy advisor to inflate his forecasts to signal his type to smart investors. We show that such a Bayesian-Nash equilibrium exists at date 0 . While smart advisees properly deflate this upward bias, naive investors unfortunately take what the advisor says at face value.

We show that a price bubble can arise as a result of this signaling equilibrium. It is important to note that the assumption about heterogeneity in advisor types (tech-savvies versus old-fogies) does not bias the results in our favor. To the contrary, this assumption, in combination with our assumption of investor heterogeneity, would tend to produce a downward bias in prices since naive investors take whatever old-fogies say at face value. In other words, the effect of optimistic signaling by well-intentioned tech-savvies has to be strong enough to overcome this baseline downward bias. It is not clear ex ante that this need be the case. However, we show that such a technology price bubble does exist when there is a sufficient 
number of naive investors guided by tech-savvy advisors.

To develop intuition for the price bias, let's consider two polar cases. First, suppose that there are only smart investors in the economy. In equilibrium, tech-savvy advisors will tend to bias their forecasts upward so as to distinguish themselves from old-fogies. However, smart investors understand this and in equilibrium will adjust their beliefs accordingly. In this case, price will be an unbiased signal of fundamentals. Next, suppose that there are only naive investors in the economy. In equilibrium, tech-savvy advisors will honestly disclose their signals since they do not worry about the ability of naive investors to infer their type. In this case, however, price will typically contain a downward bias due to the pessimistic recommendations of old-fogies, which the naive investors take at face value.

When both types of investors are present in the economy, the price could be upwardly biased. Tech-savvy advisors will bias their messages upward, and the extent of this bias increases with the fraction of smart investors. While smart investors can de-bias these messages, naive investors are unable to do so. Due to short sales constraints, the price is determined by the marginal buyer and is not affected by investors with a lower valuation. If the marginal investor is a naive advisee of a tech-savvy, then price will be upwardly biased.

Our theory yields testable implications. For instance, unlike models such as Delong, Shleifer, Summers and Waldmann (1990), the degree of mispricing in our model is largest when there are both sets of investors in the economy. Furthermore, we consider a number of robustness issues. We show that our main results survive when we loosen two assumptions: (1) allow old-fogies to send biased messages at a cost just like tech-savvies and (2) allow an investor at date 0 to observe the recommendations of other advisors as well. We also consider a number of extensions. In our model, smart investors are worried about unduely pessimistic advisors. However, due to short sales constraints, our pricing results would survive even when smart investors are worried about unduely optimistic advisors (dreamers). Importantly, our results are robust to allowing for both dreamers and old-fogeys to simultaneously be in the economy (see Section 3.3).

Our model is technically about a price bias and not about bubbles. We intentionally neglect the key element of speculative trading (i.e., buying in anticipation of capital gain) modelled elsewhere to keep things simple. But it is similar in spirit to models of speculative 
trading driven by heterogeneous beliefs and offers an important new rationale for investor divergence of opinion.

Our theory is related to the literature on costly signaling (see, e.g., Kreps, 1990; Fudenberg and Tirole, 1991). A key theme that this paper shares with earlier work is that concerns about reputation can affect the actions of agents who try to shape their reputations (Holmstrom and Ricart i Costa, 1986; Holmstrom, 1999). Previous studies have shown that reputational incentives can lead agents to take perverse actions, such as saying the expected thing which may lead to information loss (Scharfstein and Stein, 1990; Ottaviani and Sorensen, 2006), adopting a standard of conformist behavior (Bernheim, 1994) or making politically correct statements so as to not look racist (Morris, 2001). More specifically, our model, similar to Morris (2001) but unlike the others, emphasizes the perverse reputational incentives of a wellintentioned advisor: in our model, the well-intentioned tech-savvy advisor engages in costly signaling at date 0 so as to better help future investors. This contrasts with career-concernsbased models such as Scharfstein and Stein (1990) in which the advisor does not know his own type and engages in signal jamming to achieve a better reputation for his own personal gain. Our work departs from the existing literature on reputational signaling by focusing on the interaction of sophisticated agents (tech-savvies and smart investors) and naive agents (old-fogies and naive investors), in a model that is geared toward examining implications for asset pricing.

Finally, our paper complements interesting recent work by Hirshleifer and Teoh (2003) on the disclosure strategies of firms when some of their investors have limited attention. Like us, they emphasize the importance of introducing boundedly rational agents in understanding the effect of disclosures on asset prices. Unlike us, they focus on how the presentation of information may lead to different results with inattentive investors and the resulting incentives of managers to potentially manipulate earnings to fool inattentive investors.

Our paper is organized as follows. We present the model and discuss related empirical implications in Section 2. We consider robustness and extensions in Section 3. In Section 4, we conclude with a reinterpretation of the events of the Internet period in light of our findings. Proofs are presented in the Appendix. 


\section{Model}

\subsection{Set-up}

We consider the pricing of a single traded asset, which we call the new technology or tech stock. There are three dates, denoted by $t=0,1,2$. The stock pays a liquidating dividend at $t=2$ given by

$$
v=\theta+\epsilon,
$$

where $\theta$ is uniformly distributed on the interval $[0,1]$, and $\epsilon$ is normally distributed with a mean of zero and a variance of $\sigma^{2}$.

There are two types of advisors in the economy: those who are tech-savvy (with a mass of $\pi_{0} \in[0,1]$ in the population) and those who are old-fogies (with a remaining mass of $1-\pi_{0}$ ). Advisor type is unknown to investors. Tech-savvy advisors observe $\theta$ (i.e., they understand the new technology) and send a report to investors at $t=0$, denoted by $s_{0}^{T S}$. We assume that tech-savvy advisors are well-intentioned in two respects: they want to tell the truth, and they also want to maximize the welfare of their advisees at $t=1$. The truth-telling preference is captured by an assumption that tech-savvies incur a dishonesty cost if they report a signal different from the truth. This cost is given by

$$
c\left(s_{0}^{T S}-\theta\right)^{2},
$$

where $c>0$. As we shall see, a tech-savvy advisor may choose to incur some dishonesty cost and strategically bias his report upward to improve the welfare of his future clients. ${ }^{8}$ In contrast to the tech-savvy advisors, old-fogies do not understand the new technology and can only send a report that is a downward-biased version of the truth. We assume that old-fogies are not aware of their bias and truthfully report their common belief at $t=0:^{9}$

$$
s_{0}^{O F}=a \theta,
$$

\footnotetext{
${ }^{8}$ For simplicity, we assume that tech-savvy advisors have a dishonesty cost at $t=0$ instead of explicitly incorporating the welfare of the advisees at $t=0$. Our results remain when incorporating their welfare but the conditions are less transparent.

${ }^{9}$ We will relax this assumption in Subsection 3.2 by allowing old-fogies to inflate their signals by incurring a dishonesty cost. We will show that this extension does not affect our main results.
} 
where $a \in[0,1)$. Thus, the report sent by the old-fogies will always be a fraction of the true value.

There are also two types of investors at $t=0$ : smart ones (with a mass of $\rho \in[0,1]$ in the population) and naive ones (with a remaining mass of $1-\rho$ ). Investor type is unknown to advisors. Each investor is randomly matched with one advisor and only has access to the report from this advisor. ${ }^{10}$ Smart investors are aware of the existence of old-fogies and take into account the optimal reporting strategy of tech-savvy advisors in inferring their advisors' types from the messages sent by those advisors. Naive investors are not aware of the heterogeneity in advisors and simply take the messages sent to them at their face values. ${ }^{11}$ We assume that both smart and naive investors are risk neutral and take positions to maximize their expected terminal wealth. We also assume that investors cannot short sell shares and there is an upper bound to the number of shares an investor can hold, which we denote by $k$.

At $t=1$, the advisors are matched with a new set of investors. For simplicity, we assume that these investors are risk neutral. Each of these investors has an opportunity to invest in a different risky (new technology) project. The fixed cost of the project is $I$, which is a constant between 0 and 1 . The payoff of the project is $f$, which is uniformly distributed on the interval $[0,1] . f$ is independent of $\theta$. Tech-savvy advisors observe $f$ and send a report to investors at $t=1$, denoted by $s_{1}^{T S}$. They continue to want to maximize the welfare of their new advisees and incur a dishonesty cost per advisee of

$$
c\left(s_{1}^{T S}-f\right)^{2},
$$

where $c>0$, if their report differs from the truth. Old-fogies again do not understand this new technology, and they send a signal at $t=1$ given by

$$
s_{1}^{O F}=a f,
$$

where $a \in[0,1)$. We impose a parameter restriction that $a \geq I$. This restriction ensures that at least in some states of the economy an old-fogey advisor would advise investors to invest

\footnotetext{
${ }^{10}$ We will allow smart investors to access reports from other advisors in the extension to our main model developed in Subsection 3.2.

${ }^{11}$ This assumption fits with empirical evidence reported by Malmendier and Shantikumar (2004) about the inability of individual investors to see through the incentives of sell-side analysts.
} 
in the project. In addition, we assume that each advisor at $t=1$ is randomly matched with $n$ advisees. Advisor type is unknown to investors.

At $t=1$, investors again will rely on the single advisor with whom they are matched in deciding whether to make an investment. Investors only receive information about the past reports (at $t=0$ ) of the individual advisors with whom they are matched. Again, there are two types of investors at $t=1$. The smart investor uses the past report from his advisor to update his belief at $t=1$ about his advisor's type, which we denote by $\pi_{1}$. Naive investors again just take whatever their advisors tell them at face value.

The motivation for the $t=1$ set-up is that it is a reduced-form model meant to capture a stream of future advising engagements in an advisor's career. More specifically, one can think of the advisor as a sell-side analyst at date 0 who becomes a consultant to hedge funds or corporations on other projects later in his career (date 1). Those client institutions at date 1 have information regarding his track record as a sell-side analyst. The parameter $n$ captures the number of such future advising engagements. For simplicity, we have assumed that each advisor interacts with the same number of advisees at $t=1$. More realistically, advisors with better reputations, i.e. higher $\pi_{1}$ 's, would attract a larger number of advisees at date 1 . This would only help to strengthen our results.

\subsection{Equilibrium at $t=1$}

We begin by deriving a Bayesian-Nash equilibrium for the reporting strategy of the tech-savvy advisors and the investment policies of investors at date 1 . In characterizing this equilibrium, we will take as given the following property of the date 0 equilibrium: $\pi_{1}$, the probability that the smart investor assigns to the tech-savvy advisor type at date 1, can only take three values depending upon the report sent at $t=0: 0, \pi_{L}$ (a constant) and 1 . We will show that this condition indeed characterizes the outcome from the game at $t=0$ in the next sub-section.

\subsubsection{Smart investors have perfect information about advisor type: $\pi_{1}=1$ or $\pi_{1}=0$}

We begin our analysis of the date 1 equilibrium with the case in which a smart investor knows for sure whether his advisor is tech-savvy or an old-fogey. We will look for an equilibrium in 
which the tech-savvy advisor tells the truth and investors follow the efficient investment rule of investing when their expected values of $f$ are greater than $I$ (the fixed cost of investing).

Proposition 1 Suppose that $\pi_{1}=1$ or $\pi_{1}=0$. A Bayesian-Nash equilibrium at $t=1$ consists of the following profiles. The tech-savvy advisor truthfully reports his information, i.e. $s_{1}^{T S}=f$. The old-fogey reports $s_{1}^{O F}=$ af by assumption. A smart investor is able to deduce $f$ from the message sent by his advisor, denoted by $s_{1}$, and invests if $f \geq I$ and does not invest if $f<I$. A naive investor invests if $s_{1} \geq I$ and does not invest if $s_{1}<I$.

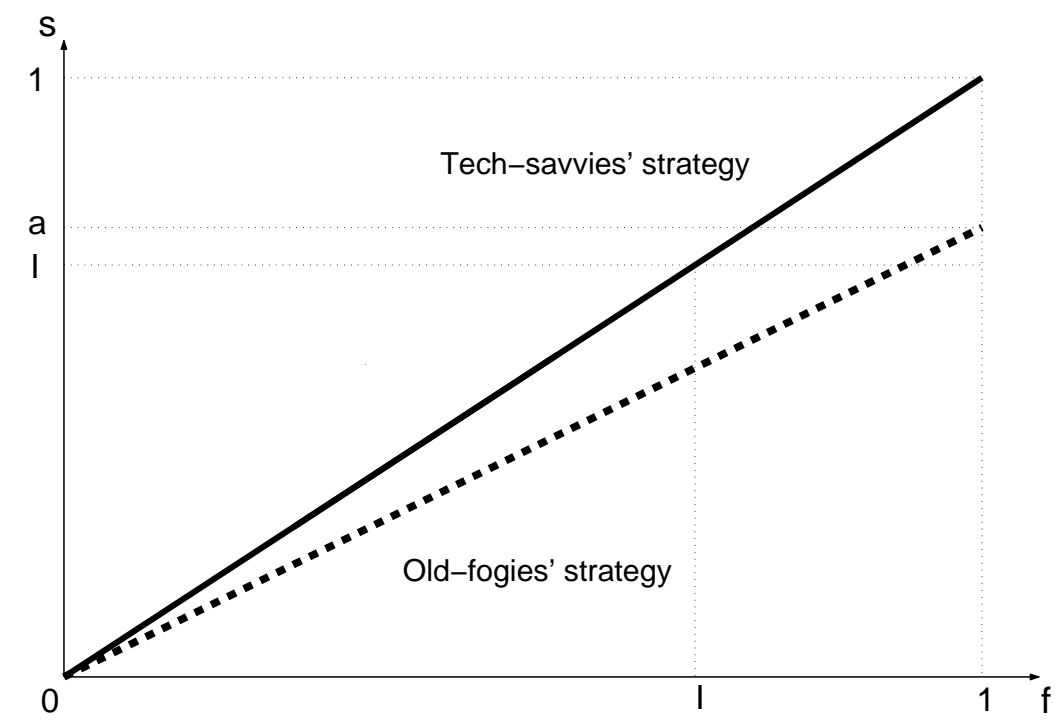

Figure 1: Advisors' strategies at $t=1$ when investors have perfect information about advisor type. The solid line plots tech-savvy advisors' strategy for different values of $f$, while the dashed line plots old-fogey advisors' strategy.

Fig. 1 illustrates the reporting strategies of tech-savvy and old-fogey advisors. Let's check that this is indeed a Bayesian-Nash equilibrium. Given the reporting strategies of the two types of advisors and the perfect information about advisor type, the smart investor can deduce $f$ and hence employs the efficient investment rule: invest only if $f \geq I$. His expected gain is

$$
E[\max (f-I, 0)]=\int_{I}^{1}(f-I) d f=\frac{1}{2}(1-I)^{2} .
$$


There is nothing to check for the naive investors since we assume that they always listen to whatever message is sent and invest only if $s_{1} \geq I$. They make an efficient investment decision if their advisor happens to be tech-savvy but may under-invest if their advisor happens to be an old-fogey.

Given the investment strategies of the two types of investors, it is optimal for a techsavvy advisor to report the truth. He has nothing to gain from deviating from the truth because the smart investor knows his type while the naive investor listens to whatever he says. Furthermore, he would incur a dishonesty cost by lying. There is nothing to check for old-fogies since we assume that they always report $s_{1}^{O F}=a f$. We therefore have proven that the profiles described in Proposition 1 constitute a Bayesian-Nash equilibrium.

\subsubsection{Smart investors have imperfect information about advisor type: $\pi_{1}=\pi_{L}$}

When smart investors have imperfect information about advisor type at date 1 , i.e. $\pi_{1}=$ $\pi_{L}$, then a tech-savvy advisor has an incentive to report a downward-biased signal of $f$ for realizations of $f$ that are neither extremely high nor extremely low. Since a smart investor does not have perfect information about his advisor's type, he will infer that signals less than $I$ may be sent by old-fogies in situations where $f \geq I$, which could lead him to invest when he should not. A tech-savvy advisor can alleviate this problem by discretely biasing his message downward so as to communicate to a smart advisee that his message must be coming from a tech-savvy advisor. In doing so, however, the tech-savvy advisor incurs some dishonesty cost in equilibrium. As we will show in the next subsection, the date 1 dishonesty penalty creates an incentive for a tech-savvy advisor to incur some initial dishonesty cost at $t=0$ so as to convince future investors of his type.

We begin by formally constructing the Bayesian-Nash equilibrium of the $t=1$ sub-game when $\pi_{1}=\pi_{L}$.

Proposition 2 Suppose $\pi_{1}=\pi_{L}$. A Bayesian-Nash equilibrium consists of the following profiles. A tech-savvy advisor's reporting strategy is given by

$$
s_{1}^{T S}=\left\{\begin{array}{ccc}
f & \text { if } & f \geq f^{*} \\
b I & \text { if } & b I \leq f<f^{*} \\
f & \text { if } & f<b I
\end{array}\right.
$$


where

$$
b=\frac{1}{\pi_{L L}+\left(1-\pi_{L L}\right) / a} \in(a, 1)
$$

with

$$
\pi_{L L}=\frac{\pi_{L}}{\pi_{L}+\left(1-\pi_{L}\right) / a}<\pi_{L}
$$

and $f^{*}$ solves the equation

$$
c\left(f^{*}-b I\right)^{2}=\rho\left(I-f^{*}\right) .
$$

The solution of this equation is given by

$$
f^{*}=\frac{1}{2} \sqrt{(\rho / c-2 b I)^{2}+4\left(\rho I / c-b^{2} I^{2}\right)}-\frac{1}{2}(\rho / c-2 b I)
$$

and $b I<f^{*}<I$. The old-fogey reports $s_{1}^{O F}=$ af by assumption. After observing a signal $s_{1}$ sent by his advisor, a smart investor will invest if $s_{1}>b I$ and does not invest if $s_{1} \leq b I$. $A$ naive investor invests if $s_{1} \geq I$ and does not invest if $s_{1}<I$.

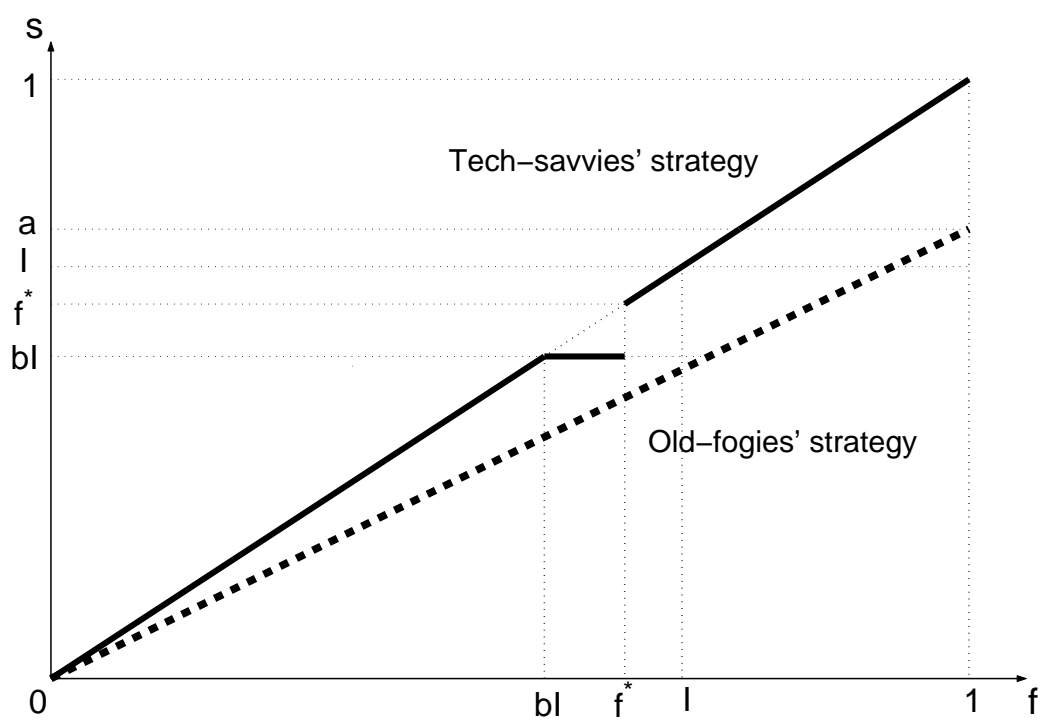

Figure 2: Advisors' strategies at $t=1$ when investors have imperfect information about advisor type. The solid line plots tech-savvy advisors' strategy for different values of $f$, while the dashed line plots old-fogey advisors' strategy. 
The proof of this proposition is in the Appendix. Fig. 2 illustrates the tech-savvy advisor's reporting strategy described in Proposition 2. The tech-savvy advisor deflates his signal to $b I$ when the fundamental variable $f$ is between $b I$ and $f^{*}$ and truthfully reports his signal when $f$ is outside of this region. Note that $(b I, I)$ is the region of fundamental value in which smart investors might potentially confuse a truthful signal from a tech-savvy advisor with a downward biased signal from an old-fogey advisor and make an inferior investment. To offset this identification problem, the optimal reporting strategy is for the tech-savvy advisor to downward bias his signal when $f$ is between $b I$ and $f^{*}$, where $f^{*}$ is a cut-off value given in the proposition. Given the tech-savvy advisor's reporting strategy, a smart investor advised by the tech-savvy advisor avoids an inferior investment when $f$ is between $b I$ and $f^{*}$, but still takes an inferior investment when $f$ is between $f^{*}$ and $I$.

\subsubsection{The gain from improved reputation for a tech-savvy advisor}

Having characterized our Bayesian-Nash equilibrium across the varying states of informational completeness regarding advisor type, we now consider the value of the advisor's reputation from the perspective of a tech-savvy advisor. The advisor's reputation will affect the investment strategy of smart investors but has no effect on naive investors. If a techsavvy advisor has a perfect reputation, a smart investor's welfare is given by the expression

$\int_{I}^{1}(f-I) d f$, which we presented earlier in equation (6). Accordingly, the value of a perfect reputation to a tech-savvy advisor is

$$
V_{1}=n \rho \int_{I}^{1}(f-I) d f
$$

which is proportional to the number of advisees he has and the probability that each one is smart.

If the tech-savvy advisor has an imperfect reputation, the expected investment profit to a smart investor in our Bayesian-Nash equilibrium is

$$
\int_{f^{*}}^{1}(f-I) d f,
$$

since the investor will end up investing when the signal is above $f^{*}$. With an imperfect reputation, the tech-savvy advisor incurs a dishonesty cost in equilibrium when the fundamental 
variable is between $b I$ and $f^{*}$. The expected cost per advisee of deflating his message in those states is

$$
\int_{b I}^{f^{*}} c(f-b I)^{2} d f
$$

Since the tech-savvy advisor cares about both his own dishonesty cost and the smart investors' gain from investment, the value he obtains from an imperfect reputation is given by

$$
V_{2}=n \rho \int_{f^{*}}^{1}(f-I) d f-\int_{b I}^{f^{*}} n c(f-b I)^{2} d f .
$$

Hence, the incremental gain to the tech-savvy advisor from establishing a perfect reputation is

$$
V_{1}-V_{2}=n \rho \int_{f^{*}}^{I}(I-f) d f+\int_{b I}^{f^{*}} n c(f-b I)^{2} d f
$$

The first term represents a gain from preventing smart investors from making inefficient investments in inferior projects, and the second term represents a gain from avoiding the dishonesty cost. We derive some simple comparative statics for this gain from a better reputation.

Proposition 3 The tech-savvy advisor's gain from improving his reputation, $V_{1}-V_{2}$, increases with the number of advisees ( $n$ ) and the fraction of smart investors in the population $(\rho)$; and it decreases with the fraction of tech-savvy advisors $\left(\pi_{0}\right)$ and the degree to which old-fogies behave like tech-savvies (a).

We relegate the proof of Proposition 3 to the Appendix since each of the comparative statics results can be explained with simple intuition. First, as the number of advisees $n$ at $t=1$ increases, the tech-savvy advisor has to incur more dishonesty costs. Hence, the greater the number of future advisees, the larger is the gain to establishing a better reputation early on. Similarly, having a better reputation only matters if there are smart investors around to use it. The gain to a better reputation thus increases with $\rho$. On the other hand, the better the initial reputation $\left(\pi_{0}\right)$, the less valuable is the gain from establishing a perfect reputation, and hence we find that $V_{1}-V_{2}$ decreases in $\pi_{0}$. Finally, the larger is $a$, the more old-fogies behave like tech-savvies. As the difference between old-fogies and tech-savvies 
shrinks, investment decisions become more efficient, and the gain to a tech-savvy advisor from improving his reputation diminishes.

One way to think of the signalling game at $t=1$ is that of an advisor (an analyst, consultant, CEO) without a technology background who is hired by the board of directors of a technology company to work with the company. A specific example is Louis Gertsner who took over IBM in the early nineties and is often credited with saving it. Gerstner's previous posts had been American Express and RJR Nabisco. He often describes having to face a skeptical IBM culture in his bid to turnaround IBM (see Gertsner, 2002). In the context of our model, the advisees are the engineers of IBM who are uncertain about the quality of Gertsner (whether he is a tech-savvy or an old-fogey). Gertsner had to talk the IBM engineers out of a number of investments (or changes). His uncertain reputation means that he had to exaggerate the extent to which he was against an investment to thwart it. As a result, there is a reward to developing a reputation as a tech-savvy as this will help lower the cost of having to exaggerate associated with being of an uncertain quality. This is a quite general point that transcends the specific context of analysts or CEOs. ${ }^{12}$

\subsection{Equilibrium at $t=0$}

\subsubsection{Tech-savvy advisor's reporting strategy}

As we discussed earlier, it is potentially useful for a tech-savvy advisor with good intentions to develop a good reputation among smart investors, since such a reputation would lessen the extent of inefficient investment by smart investors at $t=1$ and also reduce the advisor's dishonesty cost in that period when he tries to minimize the investment inefficiency by biasing his reports.

In this sub-section, we will construct a Bayesian-Nash equilibrium at $t=0$ in which the tech-savvy advisor biases his reports in an attempt to build a better reputation.

\footnotetext{
${ }^{12}$ Indeed, a second example that is less financially related is a professor in a department who might be thought of as being too tough (an old-fogey in terms of standards regarding hiring and not realizing that times have changed and there are more jobs now). Hence, he has to be really negative to convince his colleagues to not hire someone. A third example is a dad who might be thought of as being an old-fogey by his kid. If the dad really wants the kid not to try something new, again he has to exaggerate and really disapprove to convince his kid.
} 
Theorem 1 A Bayesian Nash equilibrium at $t=0$ consists of the following profiles. The reporting strategy of a tech-savvy advisor is

$$
s_{0}^{T S}=\left\{\begin{array}{ccc}
\theta & \text { if } & \theta \geq a \\
a & \text { if } & \theta^{*}<\theta<a \\
\theta & \text { if } & \theta \leq \theta^{*}
\end{array}\right.
$$

where $\theta^{*} \in[0, a)$ is a constant determined by

$$
\theta^{*}=\left\{\begin{array}{ll}
a-\sqrt{\frac{V_{1}-V_{2}}{c}}, & \text { if } a-\sqrt{\frac{V_{1}-V_{2}}{c}}>0 \\
0, & \text { otherwise }
\end{array} .\right.
$$

An old-fogey reports $s_{0}^{O F}$ by assumption. After observing a signal $s_{0}$ sent by his advisor, a smart investor infers the advisor's type according to the following rule: if $s_{0} \geq a$, the advisor is tech-savvy for sure $\left(\pi_{1}=1\right)$; if $\theta^{*}<s_{0}<a$, the advisor is an old-fogey for sure $\left(\pi_{1}=0\right)$; if $s_{0} \leq \theta^{*}$, the advisor's type remains unclear, and his reputation as a tech-savvy advisor is

$$
\pi_{L}=\frac{\pi_{0}}{\pi_{0}+\left(1-\pi_{0}\right) / a}
$$

which is lower than the advisor's initial reputation $\left(\pi_{0}\right)$.

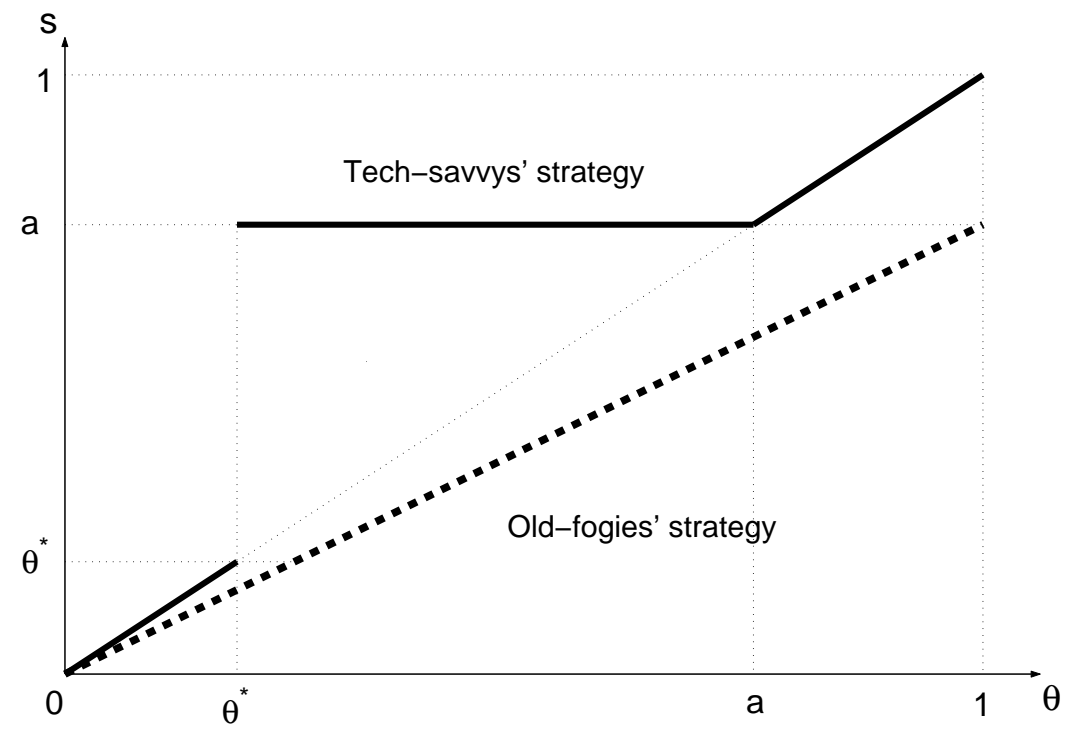

Figure 3: Advisors' strategies at $t=0$. The solid line plots tech-savvy advisors' strategy for different values of $\theta$, while the dashed line plots old-fogey advisors' strategy. 
Fig. 3 illustrates the tech-savvy advisor's reporting strategy described in Theorem 1. We now will confirm that the strategy profile constitutes an equilibrium. We begin by taking as given the smart investor's learning rule and verifying the optimality of a tech-savvy advisor's reporting strategy. First, suppose that $\theta>a$. In this case, reporting the truth reveals the tech-savvy advisor's type since an old-fogey would never send such a signal. Since the techsavvy advisor thus can achieve a perfect reputation and induce efficient investment while incurring no dishonesty cost, it is optimal for him to tell the truth when $\theta>a$. Now suppose that $\theta \in\left[\theta^{*}, a\right]$. If $\theta$ is below $a$, the tech-savvy advisor can distinguish himself from an old-fogey by inflating his signal to $a$, at a dishonesty cost of $c(\theta-a)^{2}$. Note that a techsavvy advisor would never partially inflate his report to a level below $a$, since it would hurt his reputation in equilibrium given the smart investor's learning rule. Since the dishonesty cost increases quadratically with the degree of report inflation, as the fundamental value $\theta$ decreases, the cost of inflating the report increases. When $\theta$ drops below a threshold level given by $\theta^{*}$, the dishonesty cost becomes too high relative to the gain from signaling that one is a tech-savvy for sure. $\theta^{*}$ is exactly determined by equation (18).

Finally, suppose that the fundamental value $\theta$ is below $\theta^{*}$. In this case, as we have argued above, it is too costly for the tech-savvy advisor to signal his type by inflating his message to $a$. We also observe that partially inflating the signal would not improve the advisor's reputation at all. Hence, the advisor chooses to send a truthful signal.

Next, we verify the optimality of the smart investor's inference rule, given the tech-savvy advisor's reporting strategy. If $s_{0} \geq a$, the signal must come from a tech-savvy advisor, since old-fogies would never report such a signal. Hence, $\pi_{1}=1$. If $s_{0} \in\left(\theta^{*}, a\right)$, the signal must come from an old-fogey, since tech-savvies would never report signals in this region. If $s_{0} \leq \theta^{*}$, the signal could come from either a tech-savvy or an old-fogey. The probability it is from a tech-savvy is given by Bayes Theorem:

$$
\begin{aligned}
\operatorname{Pr}\left[\text { tech-savvy } \mid s_{0}\right] & =\frac{\lambda\left(s_{0} \mid \text { tech-savvy }\right) \pi_{0}}{\lambda\left(s_{0} \mid \text { tech-savvy }\right) \pi_{0}+\lambda\left(s_{0} \mid \text { old-fogey }\right)\left(1-\pi_{0}\right)} \\
& =\frac{\pi_{0}}{\pi_{0}+\left(1-\pi_{0}\right) / a},
\end{aligned}
$$

which is exactly $\pi_{L}$ defined in equation (19). We also have verified our earlier claim about the $t=0$ equilibrium that we used to derive our $t=1$ equilibrium, namely that $\pi_{1}$ can only 
take on one of three values - 0,1 , and $\pi_{L}$.

The cut-off value $\theta^{*}$ captures the degree to which the tech-savvy advisor biases his report in order to build a better reputation. The lower is $\theta^{*}$, the greater the bias. The bias is maximal when $\theta^{*}=0$, since this implies that the tech-savvy advisor reports $a$ over the entire interval $[0, a)$. Thus, $a-\theta^{*}$ can be interpreted as a measure of the upward bias in the tech-savvy's reporting strategy.

Proposition 4 The upward bias of the tech-savvy advisor's reporting strategy (as measured by $\left.a-\theta^{*}\right)$ increases with the number of advisees at $t=1(n)$ and the fraction of smart investors $(\rho)$, and decreases with the fraction of tech-savvy advisors $\left(\pi_{0}\right)$.

The intuition for these comparative statics is similar to that underlying the behavior of $V_{1}-V_{2}$, since the upward bias in the initial report is driven by the incentive to gain a better reputation.

\subsubsection{Asset price at $t=0$}

We now derive the equilibrium price of the tech stock at $t=0$. An individual investor $i$, who observes a signal $s_{i, 0}$ from his advisor and takes the asset price $p$ as given, chooses his asset holding $x_{i}$ (shares) to maximize his expected final wealth:

$$
\max _{x_{i} \in[0, k]} x_{i}\left[E_{i}\left(\theta \mid s_{i, 0}\right)-p\right]
$$

Note that the investor cannot short sell the asset and can only take a position smaller than $k{ }^{13}$ It is direct to solve the investor's optimal position:

$$
x_{i}=\left\{\begin{array}{lll}
0 & \text { if } & E_{i}\left(\theta \mid s_{i, 0}\right)<p \\
k & \text { if } & E_{i}\left(\theta \mid s_{i, 0}\right) \geq p
\end{array}\right.
$$

The investor will stay out of the market if the price is too high relative to his belief of the asset fundamental and will take a maximum position $k$ otherwise.

To derive the equilibrium asset price, we assume that the per capita supply of the asset is $\bar{x}$ shares. To make our discussion relevant, we require that $k>\bar{x}$, i.e., investors in aggregate can hold the net asset supply.

\footnotetext{
${ }^{13}$ We could also impose an upper bound on each investor's position measured in dollars. This would slightly complicate the notation, but would not affect the qualitative results.
} 
Since each investor is paired with a single advisor, there are four possible types of investoradvisor pairs: smart investors advised by tech-savvy advisors, smart investors advised by oldfogey advisors, naive investors advised by tech-savvy advisors, and naive investors advised by old-fogey advisors, in proportions of $\rho \pi_{0}, \rho\left(1-\pi_{0}\right),(1-\rho) \pi_{0}$ and $(1-\rho)\left(1-\pi_{0}\right)$, respectively. To simplify our discussion, we assume that there are enough investors of each of these four pairs so that in aggregate any single combination can hold the net asset supply. As a result, the equilibrium asset price is determined by the highest belief among these classes of investors.

We divide the derivation of the equilibrium asset price into the following three cases.

- Case 1: $\theta>a$. In this case, tech-savvy advisors send a message equal to $\theta$, while old-fogey advisors send a message equal to $a \theta$. After observing the message from their advisors, smart investors, irrespective of the type of their advisors, will able to exactly back out the true fundamental value $\theta$. Naive investors advised by tech-savvy advisors will believe the asset fundamental is $\theta$, while those advised by old-fogey advisors will believe the fundamental is $a \theta$. Thus, the asset price is $\theta$, which is unbiased.

- Case 2: $\theta \in\left[\theta^{*}, a\right]$. In this case, tech-savvy advisors send a message equal to $a$, while old-fogey advisors send a message equal to $a \theta$. Then, among the investors, naive ones advised by tech-savvy advisors will hold the highest belief about the asset fundamental, $a$. Thus, the asset price is $a$, with an upward bias that equals $a-\theta$.

- Case 3: $\theta<\theta^{*}$. In this case, the equilibrium asset price is unbiased - given by $\theta$. First note that tech-savvy advisors send a message equal to $\theta$, while old-fogey advisors send a message equal to $a \theta$. Then, naive investors advised by tech-savvy advisors believe the asset fundamental is $\theta$, while naive investors advised by old-fogey advisors believe that it is $a \theta$. Smart investors cannot exactly identify whether their advisors are techsavvy or old-fogey and will assign a probability $\pi_{L}$, given in equation (19), to their advisors as tech-savvy. Then, if a smart investor receives a message $\theta$ from his advisor, he knows that the actual asset fundamental is either $\theta$ or $\theta / a$, with probabilities of $\pi_{L}$ and $1-\pi_{L}$, respectively. However, this smart investor would not bid a price equal to the expected asset fundamental, $\pi_{L} \theta+\left(1-\pi_{L}\right) \theta / a$, because of the winner's curse. If the asset fundamental is $\theta / a$, then naive investors advised by tech-savvy advisors would 
bid $\theta / a$. Thus, if the smart investor bids $\pi_{L} \theta+\left(1-\pi_{L}\right) \theta / a$, he is cursed to receive the asset because this implies that no one is bidding $\theta / a$. Aware of this curse, any smart investor receiving a message $\theta$ would only bid a price $\theta$. Overall, the highest bid in the market would be $\theta$, and so is the asset price.

Summarizing the three cases discussed above, we obtain the following theorem regarding the existence of a technology bubble.

Theorem 2 When there is a sufficient number of naive investors advised by tech-savvy advisors, the equilibrium stock price is identical to the tech-savvy advisors' signal:

$$
p=\left\{\begin{array}{ccc}
\theta & \text { if } & \theta \geq a \\
a & \text { if } & \theta^{*}<\theta<a . \\
\theta & \text { if } & \theta \leq \theta^{*}
\end{array} .\right.
$$

Thus, tech-savvy advisors' message inflation would directly lead to a price bubble, i.e., the asset price is upward biased by $a-\theta$ for asset fundamental $\theta$ between $\theta^{*}$ and $a$.

\subsection{Empirical Implications}

In this subsection, we develop some testable implications of our model in the following proposition:

Proposition 5 The price bubble (bias) is maximized when there is a mix of naive and smart investors. The recommendation bias on the part of the tech-savvy advisors increases with the proportion of smart investors.

It is straightforward to prove this proposition. First note that when there are only smart investors in the market, tech-savvy advisors would have the greatest incentive to signal their type by inflating their signals, but smart investors understand this and will de-bias the signals accordingly. Thus, there is no price bias on average. When there are only naive investors in the market, tech-savvy advisors have no incentive to inflate their signals. As a result, there is no price bias either. Taken together, the price bias is maximized when there is a mix of naive and smart investors. Furthermore, the property of tech-savvy advisors' recommendation bias follows from Proposition 4. 
The first prediction from Proposition 5 involves the relationship between price bias and $\rho$. Suppose that we take the market-to-book ratio of a stock to be a proxy for over-valuation. The caveat here is that the market-to-book ratio depends on risk and future returns. So these other factors have to be controlled for to the extent possible. But lets assume that this proxy picks up to some degree over-valuation and in addition that institutional investors are smart and individual investors are naive. Then our model predicts that in a cross-section of stocks, this ratio is non-linear in the heterogeneity of institutional and individual investors' holdings in the stock. In other words, our model predicts that the market-to-book ratio will be smaller when stock holders are exclusively retail or exclusively institutional and larger when there is a mix of both. This strikes us as being a genuinely testable implication.

Nonetheless, this nonlinear pattern might also emerge in a standard asymmetric information model in which institutional investors are (better) informed agents and individual investors are uninformed (Grossman and Stiglitz, 1980). In this setting, the unconditional equilibrium price is a non-linear function of the fraction of agents and in fact there are parameter values for which the pricing function is first increasing and then decreasing in the fraction of informed agents. ${ }^{14}$ In other words, to distinguish between our model and alternatives, one needs to simultaneously look at the second prediction from our comparative statics exercise on $\rho$ - that the recommendation bias is increasing in $\rho$. Using our previous interpretation of institutional investors as smart and individual investors as naive, our model predicts that we should see more optimistic recommendations issued by analysts on stocks in which the investors are mostly institutional and less optimistic recommendations on stocks in which the investors are mostly individuals. ${ }^{15}$

Ideally, we would obtain forecasts of buy-side analysts to conduct this test as we have less confidence in the prospects for testing this prediction using sell-side analyst data since their incentives are known to be influenced by investment banking and trading commissions. In other words, they do not have the purely good intentions as do the advisors in our model. Unfortunately, buy-side analyst data is harder to come by than data for the sell-side. Nonetheless, if one were to control for these offsetting incentives to the greatest extent pos-

\footnotetext{
${ }^{14}$ We thank the referee for pointing this out to us.

${ }^{15}$ Here we are assuming that the distribution of advisor types is roughly the same across stocks of different characteristics.
} 
sible (perhaps by focusing on those sell-side analysts from purely objective research shops), it would be interesting to see whether these two predictions simultaneously hold true in the data.

We discuss below the case where investors are concerned about advisors being unduely optimistic. We call such advisors dreamers. We show that if there are dreamers instead of oldfogies, then the recommendation bias of tech-savvy decreases with $\rho$ since tech-savvy advisors will want to deflate their signals as we explain below. We think the old-fogey assumption makes more sense for the Internet period. But in general, one could look at the relationship between bias and the mix of investors to deduce which of these assumptions is valid.

\section{Robustness}

\subsection{Other equilibria}

In this paper, we construct an equilibrium at $t=0$ in which a tech-savvy advisor biases his message to $a$ (or slightly above $a$ ) because there is no possibility that an old-fogey would deliver such a message, given that an old-fogey's message support is on the interval $[0, a]$ by assumption. Alternatively, one could attempt to construct an equilibrium in which the tech-savvy advisor biases his message to some other value, say $a_{0}$, where $a_{0}<a$. Such an equilibrium would offer the advantage of lowering the dishonesty cost incurred by the techsavvy type. Suppose that the tech-savvy advisor commits to reporting $a_{0}$ for realizations of fundamental value $\theta$ around $a_{0}$. If smart investors know that only tech-savvy advisors say $a_{0}$ with a high probability, then tech-savvy advisors may be able to signal their type more cost-efficiently. However, this type of equilibrium requires more public information or coordination between tech-savvy advisors and smart investors than the one in which messages are biased all the way up to $a$, or slightly higher than $a$. Indeed, biasing reports to slightly above $a$ is a natural strategy for signaling by tech-savvy advisors, since it arises naturally out of the non-overlapping support of old-fogies and smart investors at $a$. The strategy of biasing to $a_{0}$ would require more public knowledge, e.g. via a pre-game announcement that $a_{0}$ is a focal message for tech-savvy advisors. Consequently, we focus on the equilibrium centered on $a$, though we acknowledge the possibility of other equilibria requiring more pre-game coordination. 


\subsection{Alternative assumptions}

Our results depend on two assumptions. First, old-fogies always report a downward-biased signal. Second, each investor at $t=0$ only observes the message sent by his advisor. What happens if old-fogies are allowed to send biased messages at a cost, just like tech-savvies? And what if an investor at $t=0$ can observe the recommendations of other advisors as well?

In this subsection, we extend our model to relax these two assumptions. This extension yields several new insights. Notably, old-fogies want to bias their recommendations upwards at $t=0$. However, tech-savvies still can separate themselves from old-fogies by inflating their recommendations to a level that is too costly for old-fogies to mimic. Such separation is feasible when tech-savvies' true beliefs are sufficiently above those of old-fogies. Otherwise, tech-savvies truthfully report their beliefs and are mimicked by old-fogies, resulting in a pooling of the two types. Since naive investors take their advisors' signals at face value, we show that a bubble still can arise even when we relax these two key assumptions.

In order to solve the model in this more general setting, however, we need to make additional assumptions related to the off-equilibrium beliefs of market participants. While we think these assumptions are reasonable, other equilibria could arise under alternative assumptions about their off-equilibrium beliefs, as is commonly the case with Bayesian-Nash equilibria. In this sense, our solution here is more fragile than that of our benchmark model.

We adopt the same set-up as in Section 2.1. At $t=0$, both tech-savvy and old-fogey advisors form their beliefs about a new technology $\theta$. While the tech-savvies' belief is correct $\left(\hat{\theta}^{T S}=\theta\right)$, the old-fogies' belief is biased downward $\left(\hat{\theta}^{O F}=a \theta\right)$. Both types of advisors report signals to their advisees based on their beliefs. Extending our basic model, we assume that old-fogies, like tech-savvies, can choose to bias their signals (recommendations) relative to their own beliefs, subject to a dishonesty cost:

$$
c\left(s_{0}^{O F}-\hat{\theta}^{O F}\right)^{2}
$$

In addition, we assume that at $t=0$ there are many advisors in the market covering the same technology stock, and their signals are observable not only to their advisees, but also to other smart investors. Consequently, smart investors can compare signals from all advisors

to infer the asset fundamental $\theta$. We assume that a naive investor continues to use only his 
advisor's signal and accepts it at face value.

At $t=1$, each advisor is matched with a new set of investors and assists them in deciding whether to invest in a new project with random liquidation value $f$ and fixed cost $I$. We now assume that both tech-savvy and old-fogey advisors can choose to bias their signals, subject to the dishonesty cost, to maximize their advisees' welfare based on their heterogenous beliefs. As before, when a tech-savvy advisor with an imperfect reputation at $t=1$ believes that the project's liquidation value $f$ is below the cost $I$, smart investors might choose to invest in the project even if the advisor truthfully reports his pessimistic belief. This is because smart investors attribute a positive probability to the advisor being an old-fogey.

We now characterize our equilibrium solution of this extended model. At $t=1$, the optimal communication strategy on the part of a tech-savvy advisor with an imperfect reputation (i.e. probability of being tech-savvy) $\pi \in(0,1)$ is to bias his messages downward over some beliefs so as to communicate to his smart advisee that certain messages could not be coming from him. An old-fogey advisor with a reputation $\pi \in(0,1)$ also has the same incentive to deflate his recommendation over the same belief region.

Proposition 6 summarizes the Bayesian-Nash equilibrium at $t=1$, with the proof given in the Appendix.

Proposition 6 A Bayesian-Nash equilibrium at $t=1$ consists of the following profiles. The reporting strategy of a tech-savvy advisor with a reputation of $\pi \in[0,1]$ of being tech-savvy, is

$$
s_{1}^{T S}\left(\hat{f}^{T S}\right)=\left\{\begin{array}{ccc}
\hat{f}^{T S} & \text { if } & \hat{f}^{T S} \geq f^{*} \\
d I & \text { if } & d I \leq \hat{f}^{T S}<f^{*} \\
\hat{f}^{T S} & \text { if } & \hat{f}^{T S}<d I
\end{array}\right.
$$

where $\hat{f}^{T S}$ is the advisor's belief about the project fundamental $f$. The parameters $f^{*}$ and $d$ are determined by the following equations:

$$
\begin{aligned}
n \rho\left(I-f^{*}\right) & =n c\left(f^{*}-d I\right)^{2} \\
\frac{1}{2}\left(f^{*}+d I\right) & =b(\pi) I
\end{aligned}
$$


where

$$
b(\pi)=\frac{1}{\hat{\pi}+(1-\hat{\pi}) / a}, \text { with } \hat{\pi}=\frac{\pi}{\pi+(1-\pi) / a} .
$$

The reporting strategy of an old-fogey advisor with reputation $\pi$ is the same as that of a tech-savvy advisor with the same reputation:

$$
s_{1}^{O F}\left(\hat{f}^{O F}\right)=\left\{\begin{array}{ccc}
\hat{f}^{O F} & \text { if } & \hat{f}^{O F} \geq f^{*} \\
d I & \text { if } & d I \leq \hat{f}^{O F}<f^{*} \\
\hat{f}^{O F} & \text { if } & \hat{f}^{O F}<d I
\end{array}\right.
$$

where $\hat{f}^{O F}$ is the advisor's belief about the project fundamental $f$.

After observing the signal, a naive investor invests if and only if the signal is above I. A smart investor does not invest if the signal is equal to or below $d I$ and invests otherwise.

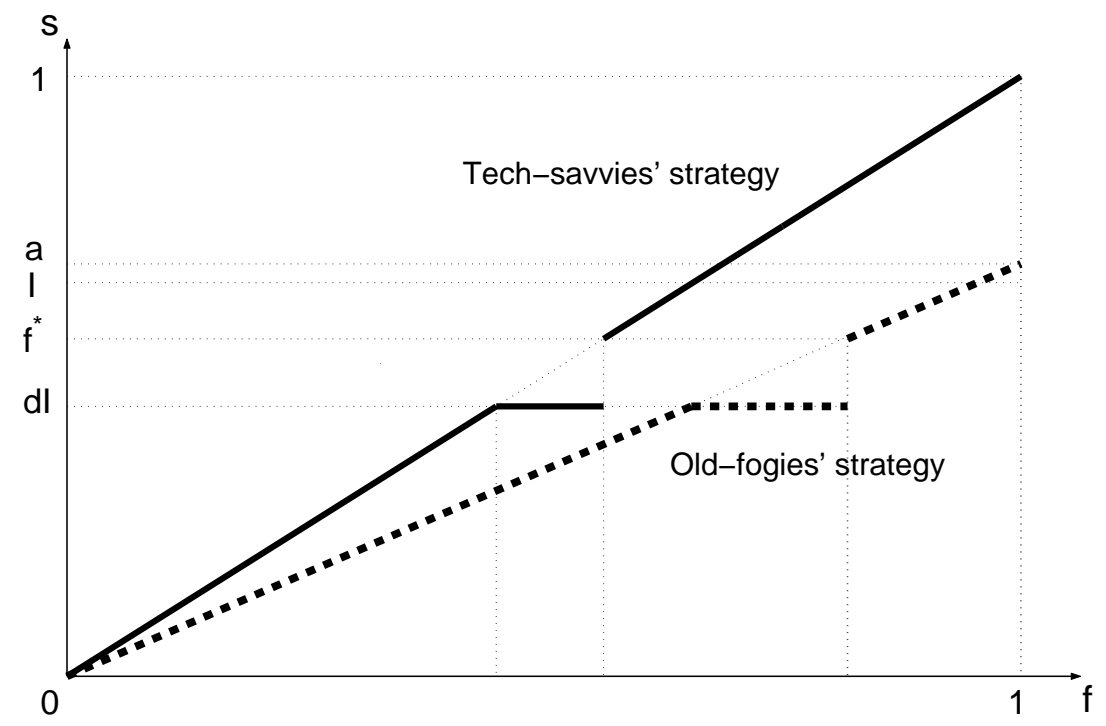

Figure 4: Advisors' strategies at $t=1$ with imperfect information about type. The solid line plots tech-savvy advisors' strategy for different values of $f$, while the dashed line plots old-fogey advisors' strategy.

Proposition 6 shows that tech-savvy and old-fogey advisors who possess the same reputation and the same belief about the project fundamental will choose to report the same signal, as illustrated in Fig. 4. The proof of Proposition 6 is standard and is given in the 
Appendix. We verify the optimality of advisors' reporting strategies by taking the investors' learning rules as given, and we subsequently verify the optimality of investors' learning rules by taking advisors' reporting strategies as given. Since in equilibrium advisors do not report signals in the region $\left(d I, f^{*}\right)$, we need to specify an off-equilibrium belief for smart investors if an advisor chooses to send a signal $s_{1} \in\left(d I, f^{*}\right)$. In the proof, we assume that an investor believes that such a signal could be from either a tech-savvy or an old-fogey with a belief between $s_{1}$ and $f^{*}$ and that the belief of each type of advisor is uniformly distributed on $\left(s_{1}, f^{*}\right) \cdot{ }^{16}$

According to Proposition 6, an imperfect reputation $(\pi<1)$ creates inefficiencies for both types of advisors, as both tech-savvy and old-fogey advisors need to incur dishonesty costs to avoid inefficient investment by their smart advisees when the advisors' beliefs are in $\left(d I, f^{*}\right)$. Furthermore, the smart advisee makes an inefficient investment from the advisor's perspective if the advisor's belief is in $\left(f^{*}, I\right)$. Thus, for a benevolent tech-savvy advisor with a reputation $\pi$, the expected inefficiency - equal to his dishonesty cost plus the investment loss by his advisees - is

$$
K^{T S}(\pi)=\int_{f^{*}}^{I} n \rho(I-\hat{f}) d \hat{f}+\int_{d I}^{f^{*}} n c(\hat{f}-d I)^{2} d \hat{f} .
$$

For a benevolent old-fogey advisor with a reputation $\pi$, the expected inefficiency is

$$
K^{O F}(\pi)=\int_{f^{*}}^{I} n \rho(I-\hat{f}) d \hat{f} / a+\int_{d I}^{f^{*}} n c(\hat{f}-d I)^{2} d \hat{f} / a .
$$

Note that

$$
K^{O F}(\pi)=K^{T S}(\pi) / a
$$

Based upon the expressions for $K^{T S}$ and $K^{O F}$, we can directly verify that they are monotonically decreasing with the advisor's reputation $\pi$, as stated in the following proposition.

Proposition 7 Both $K^{T S}(\pi)$ and $K^{O F}(\pi)$ decrease with $\pi$ and are zero when $\pi=1$.

Proposition 7 shows that both tech-savvy and old-fogey advisors can benefit from a good reputation. Thus, at $t=0$, tech-savvy advisors have incentives to separate themselves from

\footnotetext{
${ }^{16}$ This assumption is reasonable because in the proposed equilibrium, no type of advisor ever inflates his signal, but both types deflate their signals for some beliefs below $f^{*}$. Hence, a signal in $\left(d I, f^{*}\right)$ could come from an advisor who is attempting to deflate his signal but does not deflate it enough to the optimal level $d I$.
} 
old-fogey advisors by reporting an optimistic signal. At the same time, old-fogey advisors also have the incentive to mix with tech-savvy advisors by inflating their signals as well. Due to these incentives operating on both types, the equilibrium has two outcomes: (1) a separating outcome in which tech-savvy advisors report an extremely optimistic signal that is too costly for old-fogey advisors to match, when the fundamental is sufficiently high; and (2) a pooling outcome, in which tech-savvy advisors truthfully report their belief, and old-fogey advisors match such a recommendation, when the fundamental is not too high.

The following proposition summarizes the equilibrium, with the proof given in the Appendix.

Proposition 8 Under certain sufficient conditions, namely

$$
\begin{aligned}
& 1-a \leq \sqrt{K^{O F}(0) / c} \\
& {\left[\sqrt{K^{O F}(0)}-\sqrt{K^{T S}(\hat{\pi})}\right] / a<\sqrt{K^{O F}(0)-K^{O F}(\hat{\pi})}<\sqrt{c}(1-a) / a}
\end{aligned}
$$

where $\hat{\pi}=\frac{\pi_{0}}{\pi_{0}+\left(1-\pi_{0}\right) / a}$, we have the following Bayesian-Nash equilibrium at $t=0$.

Given a tech-savvy advisor's belief $\hat{\theta}^{T S}$, which is equal to the true value $\theta$, his reporting strategy is

$$
s_{0}^{T S}\left(\hat{\theta}^{T S}\right)=\left\{\begin{array}{ccc}
a \hat{\theta}^{T S}+z & \text { if } & \hat{\theta}^{T S} \geq \theta^{*} \\
\hat{\theta}^{T S} & \text { if } & \hat{\theta}^{T S}<\theta^{*}
\end{array}\right.
$$

where

$$
z=\sqrt{K^{O F}(0) / c}
$$

and $\theta^{*} \in(0,1)$ is defined as

$$
\theta^{*}=\frac{a}{1-a} \sqrt{\left[K^{O F}(0)-K^{O F}(\hat{\pi})\right] / c}
$$

Given an old-fogey advisor's belief $\hat{\theta}^{O F}$, which is equal to a $\theta$, his reporting strategy is

$$
s_{0}^{O F}\left(\hat{\theta}^{O F}\right)=\left\{\begin{array}{clc}
\hat{\theta}^{O F} & \text { if } & \hat{\theta}^{O F} \geq a \theta^{*} \\
\hat{\theta}^{O F} / a & \text { if } & \hat{\theta}^{O F}<a \theta^{*} .
\end{array}\right.
$$

A naive investor always takes the signal from his advisor at face value. When $\theta<\theta^{*}$, the naive investor's belief turns out to be correct; when $\theta \geq \theta^{*}$, his belief is upward biased 
when he is matched with a tech-savvy advisor and downward biased when matched with an old-fogey advisor.

Smart investors are always able to correctly infer the value of $\theta$ by comparing signals available in the market. Furthermore, when $\theta \geq \theta^{*}$, there is a separating outcome in which tech-savvy advisors inflate their signal to $a \theta+z$, while old-fogey advisors report a $\theta$. Thus, smart investors are able to identify their advisors' types when $\theta$ is high. When $\theta<\theta^{*}$, there is a pooling outcome in which all advisors send the same signal equal to $\theta$. In this case, smart investors attribute probability $\hat{\pi}=\frac{\pi_{0}}{\pi_{0}+\left(1-\pi_{0}\right) / a}$ to their advisors being tech-savvy.

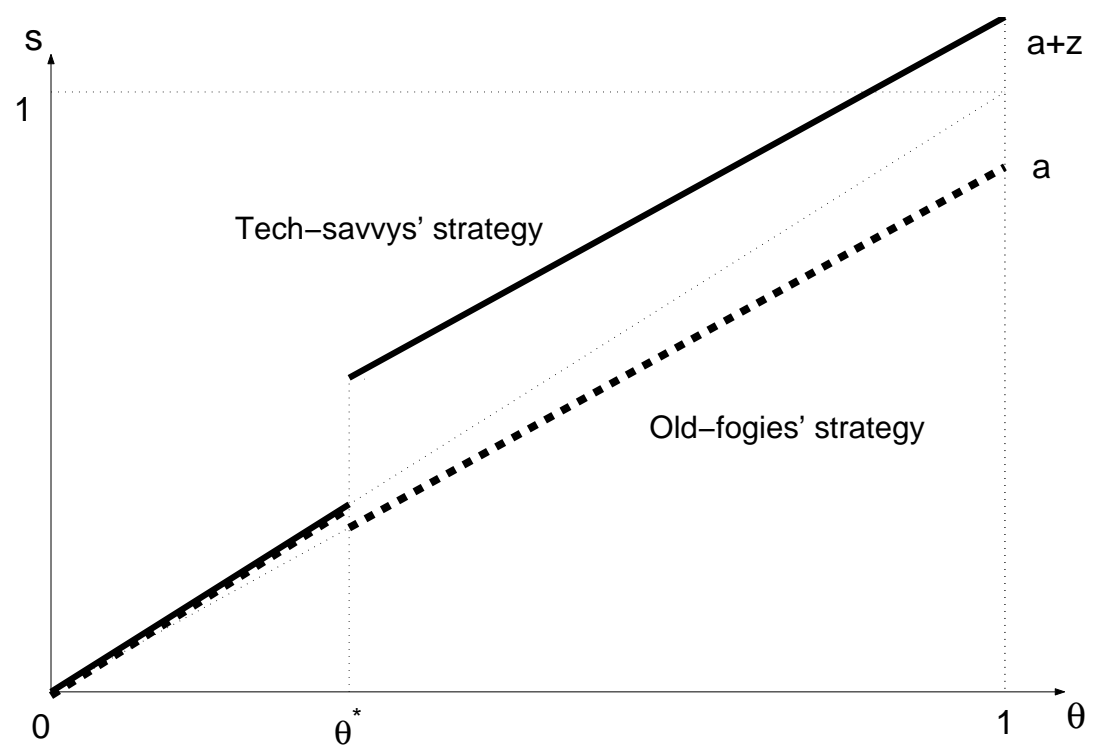

Figure 5: Advisors' strategies at $t=0$. The solid line plots tech-savvy advisors' strategy for different values of $\theta$, while the dashed line plots old-fogey advisors' strategy.

As illustrated in Fig. 5, Proposition 8 shows that when the technology fundamental $\theta$ is sufficiently high $\left(\theta \geq \theta^{*}\right)$, tech-savvy advisors are able to separate themselves from old-fogey advisors by inflating their signal. It is too costly for old-fogey advisors to match the techsavvies' signal because their belief is substantially below that of the tech-savvies. When $\theta$ is small $\left(\theta<\theta^{*}\right)$, tech-savvy and old-fogey advisors' beliefs are close enough that it becomes too costly for tech-savvy advisors to separate themselves, and consequently there is a pooling equilibrium in which old-fogies inflate their signal to match the tech-savvies' truthful report.

The proof of Proposition 8 is standard and is given in the Appendix. We again need 
to specify certain assumptions for investors' learning rules when they receive off-equilibrium signals. These assumptions are similar in spirit to those used to derive the equilibrium at $t=1$.

Because of the short sales constraints, the asset price at $t=0$ is determined by the highest belief in the market. When the asset fundamental $\theta$ is above $\theta^{*}$, the belief of those naive investors advised by tech-savvy advisors is upward biased to $a \theta+z$. As a result, the asset price is upward biased to $a \theta+z$ as well, as long as these investors in aggregate can hold the net asset supply. When $\theta$ is below $\theta^{*}$, every investor holds the correct belief, thus the asset price is unbiased.

Proposition 9 When there is a sufficient number of naive investors advised by tech-savvy advisors, the asset price at $t=0$ is determined by

$$
p= \begin{cases}a \theta+z & \text { if } \theta>\theta^{*} \\ \theta & \text { if } \theta \leq \theta^{*}\end{cases}
$$

The asset price is upward-biased when $\theta \geq \theta^{*}$ and is unbiased otherwise.

\subsection{Extensions}

We consider a number of extensions to our model. The first extension is to allow for intermediate performance feedback. In our current model, the advisors are not judged on the accuracy of their recommendations at $t=0$. We can extend our model to allow for this feedback. This feedback would weaken the incentive of the tech-savvy advisors to signal their type, but the key results would not be overturned. As is the case with any type of signaling model, we also could allow advisors to signal in other ways besides through their recommendations. While the advisor might trade off different modes of signaling, the basic insights of the model would remain unchanged.

The second extension is to replace old-fogies with dreamers, advisors who are instead unduely optimistic. The model in this case is completely symmetric to our original set-up except that tech-savvies deflate their signal to separate themselves from dreamers. However, despite tech-savvy advisors' signal deflation, the asset price would still be upward biased as long as there are enough naive investors guided by dreamers. Although smart investors 
recognize the overvaluation, they can only sit on the sideline because of the short sales constraints. We omit the analysis of this case as it is subsumed by our next extension.

The third extension is to consider the equilibrium when there are both dreamer and oldfogey advisors in the economy. Namely, we derive the equilibrium at $\mathrm{t}=0$ when there are both dreamers and old-fogies in the market, i.e. there are three type, dreamers, old-fogies and tech-savvies. The upshot is that we are able to show that there is an equilibrium with properties qualitatively similar to those in the paper and hence that our results will not fall apart with three types in the market.

More specifically, we assume that dreamers can only send an upward-biased signal about the new technology at $t=0$ :

$$
s_{0}^{D R}=b+(1-b) \theta
$$

where $b \in(0,1)$. Note that as $b$ increases, the dreamers' signal becomes more optimistic. As before, old-fogies can only send a downward-biased signal:

$$
s_{0}^{O F}=a \theta,
$$

where $a \in[0,1)$. Tech-savvies have a correct belief about $\theta$, but can choose to bias their reports for the purpose of signalling. We denote the initial distribution of the three types of advisors, dreamers, old-fogies, and tech-savvies, by $\pi_{D R}, \pi_{O F}$, and $\pi_{T S}$, respectively $\left(\pi_{D R}+\right.$ $\left.\pi_{O F}+\pi_{T S}=1\right)$.

It is difficult to analyze the tech-savvies' reporting strategy in the most general case. Instead, we focus on the case where dreamers' and old-fogies' signal spaces do not overlap, i.e., the highest possible report from an old-fogey is still lower than the lowest possible message from a dreamer, $b>a$. We need this assumption of non-overlapping signal spaces for tractability.

For brevity, we focus on the $t=0$ equilibrium and the reporting strategy of tech-savvies during this period. We make some reduced form assumptions regarding the advisor's continuation value function at $t=1$. Given the non-overlapping signal spaces, there are only three possible outcomes regarding a tech-savvy's reputation at $t=1$ in equilibrium. The first is that he has a perfect reputation as a tech-savvy. We denote his value function in this case 
by $V_{T S}$. The second is that he has an imperfect reputation as a possible old-fogey but is for sure not a dreamer. We denote his value function in this case by $V_{O F}(\pi)$ with $\pi$ as the probability that smart investors assign to him as a tech-savvy. The third is that he has an imperfect reputation as a possible dreamer but is for sure not an old-fogey. We denote his value function in this case $V_{D R}(\pi)$ with $\pi$ as the probability that smart investors assign to him as a tech-savvy. It is natural to assume that both $V_{O F}(\pi)$ and $V_{D R}(\pi)$ increase with $\pi$ and are always less than $V_{T S}$. Otherwise, there would be not value of signalling at $t=0$. Like before, we assume that if the tech-savvy biases his report, he suffers a dishonesty cost: $c\left(s_{1}^{T S}-\theta\right)^{2}$.

The equilibrium at $t=0$ is summarized in the following theorem.

Theorem 3 A Bayesian Nash equilibrium at $t=0$ consists of the following profiles. The reporting strategy of a tech-savvy advisor is

$$
s_{0}^{T S}=\left\{\begin{array}{ccc}
\theta & \text { if } & \theta \geq \theta_{2}^{*} \\
b & \text { if } & b \leq \theta<\theta_{2}^{*} \\
\theta & \text { if } & a \leq \theta<b \\
a & \text { if } & \theta_{1}^{*} \leq \theta<a \\
\theta & \text { if } & \theta<a
\end{array}\right.
$$

where $\theta_{1}^{*} \in[0, a)$ is a constant determined

$$
\theta_{1}^{*}= \begin{cases}a-\sqrt{\frac{V_{T S}-V_{O F}\left(\frac{\pi_{T S}}{\pi_{T S}+\pi_{O F} a}\right)}{c},}, & \text { if } a-\sqrt{\frac{V_{T S}-V_{O F}\left(\frac{\pi_{T S}}{\pi_{T S}+\pi_{O F} / a}\right)}{c}>0} \\ 0, & \text { otherwise }\end{cases}
$$

and $\theta_{2}^{*} \in(b, 1]$ is a constant determined

$$
\theta_{2}^{*}= \begin{cases}b+\sqrt{\frac{V_{T S}-V_{D R}\left(\frac{\pi_{T S}}{\pi_{T S}+\pi_{D R} /(1-b)}\right)}{c},}, & \text { if } b+\sqrt{\frac{V_{T S}-V_{D R}\left(\frac{\pi_{T S}}{\pi_{T S}+\pi_{D R} /(1-b)}\right)}{c}}<1 \\ 1, & \text { otherwise. }\end{cases}
$$

After observing a signal $s_{0}$ sent by his advisor, a smart investor infers the advisor's type according to the following rule: if $s_{0} \geq \theta_{2}^{*}$, the advisor can either be a tech-savvy with a probability of $\frac{\pi_{T S}}{\pi_{T S}+\pi_{D R} /(1-b)}$ or a dreamer with a probability of $\frac{\pi_{D R} /(1-b)}{\pi_{T S}+\pi_{D R} /(1-b)}$; if $b<s_{0}<\theta_{2}^{*}$, the advisor is a dreamer for sure; if $a \leq s_{0} \leq b$, the advisor is a tech-savvy for sure; if 
$\theta_{1}^{*} \leq s_{0}<a$, the advisor is an old-fogey for sure; finally, if $s_{0} \leq \theta_{1}^{*}$, the advisor can either be a tech-savvy with a probability of $\frac{\pi_{T S}}{\pi_{T S}+\pi_{O F} / a}$ or an old-fogey with a probability of $\frac{\pi_{O F} / a}{\pi_{T S}+\pi_{O F} / a}$.

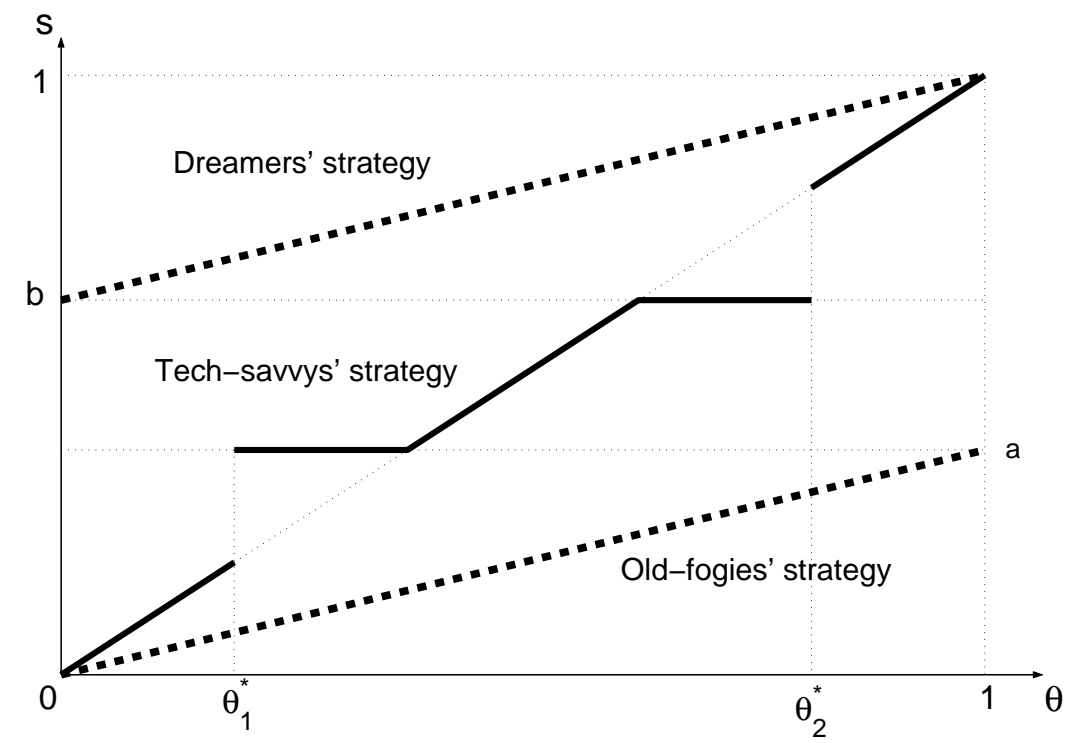

Figure 6: Advisors' strategies at $t=0$ in the presence of dreamers and old-fogies. The solid line plots tech-savvy advisors' strategy for different values of $\theta$, the top dashed line plots dreamer advisors' strategy, while the bottom dashed line plots old-fogey advisors' strategy.

Fig. 6 illustrates a tech-savvy's reporting strategies at $t=0$ in the presence of dreamers and old-fogies. Note that for high (but not too high) realizations of the fundamental, $\theta \in$ $\left(b, \theta_{2}^{*}\right)$, the tech-savvy advisor deflates his report to $b$. Intuitively, he is worried about being pooled with dreamers in this region. And for low (but not too low) realizations of the fundamental, $\theta \in\left(\theta_{1}^{*}, a\right)$, the tech-savvy advisor inflates his report to $a$. He is worried about being pooled with old-fogies in this region.

The following proposition further shows that the tech-savvy's tendency to bias his report depends on the ex ante distribution of advisors. More specifically, when investors are more concerned about their advisors being an old-fogey (i.e. $\pi_{O F}$ is higher), the tech-savvy inflates his report for a larger range of fundamental values (i.e. $a-\theta_{1}^{*}$ is bigger); while when investors are more concerned about their advisors being a dreamer (i.e. $\pi_{D R}$ is higher), the tech-savvy deflates his reports for a larger range of fundamental values (i.e. $\theta_{2}^{*}-b$ is bigger). 
Proposition 10 Keeping $\pi_{T S}$ constant, an increase in $\pi_{O F}$ (which corresponds to a decrease in $\pi_{D R}$ for the probabilities to sum up to one) would cause $a-\theta_{1}^{*}$ to rise and $\theta_{2}^{*}-b$ to fall.

Thus, our results remain with three types of advisors in the market in the sense that there is more inflation when there is more concern about old-fogies and less inflation or deflation when there is more concern about dreamers. Importantly, since there are shortsales constraints, there will be an upward price bias and the bias is greater when there is more concern about old-fogies.

\section{Conclusion}

We conclude by re-interpreting the events of the Internet period in light of our model. In the aftermath of the Internet bubble, many have cited the role of biased advisors in manipulating the expectations of naive investors. We agree with the focus on the role of advisors but observe that there is something deeper in the communication process between advisors and investors that can lead to an upward bias in prices during times of excitement about new technologies, even absent any explicit incentives on the part of analysts to sell stocks.

Our model suggests that the Internet period was a time when investors were naturally concerned about whether their advisors understood the new technology, i.e. were their advisors old-fogies or tech-savvy? Investors do not want to listen to old-fogies. As a result, well-intentioned advisors have an incentive to signal that they are tech-savvy by issuing optimistic forecasts, and this incentive is based on their desire to be listened to by future advisees. Unfortunately, naive investors do not understand the incentives of advisors to inflate their forecasts, and consequently asset prices are biased upward.

This view is not totally without empirical support. In addition to the evidence cited in the introduction, it is well known that the reports issued by sell-side analysts are typically read only by institutional investors, who for the most part do a good job of de-biasing analyst recommendations. Unfortunately, during the Internet period, many retail investors took the positive, upbeat recommendations of analysts a bit too literally. Again, this is not to say that analysts during this period were solely well-intentioned, but simply that when there are naive investors, there can be a bubble during times of technological excitement even if all 
analysts are well-intentioned.

\section{Appendix}

\subsection{Proof of Proposition 2}

To verify that the proposed strategies indeed constitute a Bayesian-Nash equilibrium, we begin by taking as given the reporting strategies of the advisors and verifying the optimality of the smart investor's investment policy. First, suppose that $s_{1} \geq I$. The message could be from a tech-savvy or an old-fogey (if $s_{1} \in[I, a]$ ). In this case, however, it does not matter to the smart investor which type of advisor sent such a signal, since the investor will infer that $f \geq I$ given the reporting strategies of the two types of advisors. Thus, the investor invests when $s_{1} \geq I$.

Next, let's suppose that $s_{1} \in\left(f^{*}, I\right)$. For a signal sent in this region of the support, the signal again could be from a tech-savvy or an old-fogey. Let $\pi_{L L}$ be the posterior probability that a signal in this region came from a tech-savvy advisor, i.e.

$$
\pi_{L L}=\operatorname{Pr}\left\{\text { tech-savvy } \mid s_{1}\right\}
$$

with $s_{1} \in\left(f^{*}, I\right)$. Then by Bayes Theorem, we have that

$$
\pi_{L L}=\frac{\lambda\left(s_{1} \mid \text { tech-savvy }\right) \pi_{L}}{\lambda\left(s_{1} \mid \text { tech-savvy }\right) \pi_{L}+\lambda\left(s_{1} \mid \text { old-fogey }\right)\left(1-\pi_{L}\right)},
$$

where $\lambda$ denotes a probability density function. Given the tech-savvy advisor's reporting strategy, the probability density of his signal is

$$
\lambda\left(s_{1} \mid \text { tech-savvy }\right)=\left\{\begin{array}{lll}
1 & \text { if } & f \in[0, b I) \\
0 & \text { if } & f \in\left(b I, f^{*}\right) \\
1 & \text { if } & f \in\left[f^{*}, 1\right]
\end{array}\right.
$$

and $\operatorname{Pr}\left(s_{1}=b I \mid\right.$ tech-savvy $)=f^{*}-b I$. Note also that since the signal from an old-fogey has uniform distribution over the interval $[0, a]$,

$$
\lambda\left(s_{1} \mid \text { old-fogey }\right)=1 / a, \quad \forall s_{1} \in[0, a]
$$

Thus, if $s_{1} \in\left(f^{*}, I\right)$, then

$$
\pi_{L L}=\frac{\pi_{L}}{\pi_{L}+\left(1-\pi_{L}\right) / a}<\pi_{L}
$$


Given such a signal, the smart investor's inference of the project fundamental is

$$
E\left[f \mid s_{1}\right]=\pi_{L L} s_{1}+\left(1-\pi_{L L}\right) s_{1} / a
$$

Thus, the investor finds it optimal to invest in the project if

$$
s_{1}>\frac{I}{\pi_{L L}+\left(1-\pi_{L L}\right) / a}=b I .
$$

Now suppose that $s_{1} \in\left(b I, f^{*}\right]$. In this case, the smart investor deduces that the signal must be from an old-fogey since a tech-savvy advisor would never send a signal in this region. Given such a signal, the smart investor's inference of the project fundamental is

$$
E\left[f \mid s_{1}\right]=s_{1} / a>\frac{b I}{a}=\frac{I}{1-(1-a) \pi_{L L}}>I .
$$

The smart investor therefore invests when $s_{1} \in\left(b I, f^{*}\right]$.

If $s_{1}=b I$, then the signal must be from a tech-savvy advisor since the reporting strategy of that type puts non-trivial mass on the signal $b I$. To see this, note that

$$
\operatorname{Pr}\left\{s_{1}=b I \mid \text { tech-savvy }\right\}=f^{*}-b I,
$$

and

$$
\operatorname{Pr}\left\{s_{1}=b I \mid \text { old-fogey }\right\}=\operatorname{Pr}\left\{s_{1} \in(b I-\epsilon, b I+\epsilon) \mid \text { old-fogey }\right\}_{\epsilon \rightarrow 0}=\left.\frac{2 \epsilon}{a}\right|_{\epsilon \rightarrow 0}=0 .
$$

Thus, the conditional probability that such a signal comes from a tech-savvy is

$$
\begin{aligned}
& \operatorname{Pr}\left\{\text { tech-savvy } \mid s_{1}=b I\right\} \\
= & \frac{\operatorname{Pr}\left(s_{1}=b I \mid \text { tech-savvy }\right) \pi_{L}}{\operatorname{Pr}\left(s_{1}=b I \mid \text { tech-savvy }\right) \pi_{L}+\operatorname{Pr}\left(s_{1}=b I \mid \text { old-fogey }\right)\left(1-\pi_{L}\right)}=1
\end{aligned}
$$

Given such an inference, the smart investor would not invest.

If $s_{1}<b I$, then the analysis is similar to the case in which $s_{1} \in\left(f^{*}, I\right) . \pi_{L L}$ again is the posterior probability that a signal in this region came from a tech-savvy advisor. Given such a signal, the smart investor's inference of the project fundamental is

$$
E\left[f \mid s_{1}\right]=\frac{s_{1}}{b} .
$$

In this case, $s_{1}<b I$, so the smart investors do not invest. We thus have shown that the postulated investment policy of the smart investors is indeed optimal given the proposed 
reporting strategy of the tech-savvy advisors and the assumed reporting strategy of the oldfogies.

We now will show that the tech-savvy advisor's reporting strategy is optimal given the investors' investment policies. Suppose that $f \geq I$, so that it is efficient for investors to invest. Then it is optimal for the tech-savvy advisor to tell the truth. Suppose that $f \in\left(f^{*}, I\right)$. In this case, investment is not efficient. Under the proposed strategy of smart investors, however, those investors will invest after observing a signal in this range. If the advisor tells the truth, then the expected cost born by smart investors is $n \rho(I-f)$. If the advisor were to bias his message, he would have to deflate it to $b I$ to prevent smart investors from investing according to the proposed investment rule. The dishonesty cost of deflating the message to $b I$ across $n$ advisees is

$$
n c(f-b I)^{2} .
$$

Since $f>f^{*}$, we find that

$$
n c(f-b I)^{2}>n c\left(f^{*}-b I\right)^{2}=n \rho\left(I-f^{*}\right)>n \rho(I-f)
$$

using the definition of $f^{*}$ given in the proposition above. As a result, there is no incentive for a tech-savvy advisor to under-report his signal in order to dissuade smart investors from investing.

Suppose that $f \in\left[b I, f^{*}\right]$. Under the proposed equilibrium strategies, the smart investor would not invest in this range of $f$, and the tech-savvy advisor incurs a dishonesty cost of $n c(f-b I)^{2}$. The tech-savvy advisor will not deviate to any signal lower than $b I$, since this would increase his dishonesty cost while having no effect on the smart investor's decision. If the advisor deviates to any signal $s_{1}>b I$, this would induce the smart investor to invest, and the cost to smart investors again would be given by $n \rho(I-f)$. If the advisor reports $b I$, then the dishonesty cost incurred by the advisor is $n c(f-b I)^{2}$. Note that when $f \in\left[b I, f^{*}\right]$,

$$
n c(f-b I)^{2} \leq n c\left(f^{*}-b I\right)^{2}=n \rho\left(I-f^{*}\right) \leq n \rho(I-f),
$$

again from the definition of $f^{*}$. Thus, it is optimal for the tech-savvy advisor to report $b I$ when $f \in\left[b I, f^{*}\right]$, since the cost of inefficient investment by smart investors outweighs the 
maximum reduction of dishonesty cost that the tech-savvy advisor could achieve by telling the truth.

Finally, if $f<b I$, then the advisor simply tells the truth since a truthful signal will lead investors to make the efficient decision to not invest.

\subsection{Proof of Proposition 3}

By integrating Eq. (16), we have

$$
V_{1}-V_{2}=\frac{n \rho}{2}\left(I-f^{*}\right)^{2}+\frac{n c}{3}\left(f^{*}-b I\right)^{3}
$$

By substituting in Eq. (10), we can transform the last Eq. into

$$
V_{1}-V_{2}=n \rho\left(I-f^{*}\right)\left[\left(\frac{1}{2}-\frac{b}{3}\right) I-\frac{f^{*}}{6}\right] .
$$

This equation directly implies that $V_{1}-V_{2}$ increases with $\rho$ and decreases with $f^{*}$.

Eq. (10) implies that $f^{*}$ increases with $b$. Eq. (8) implies that $b$ increases with $\pi_{L L}$, which also increases with $\pi_{0}$. Thus, $f^{*}$ increases with $\pi_{0}$, and $V_{1}-V_{2}$ decreases with $\pi_{0}$. Eq. (8) also implies that $b$ increases with $a$; therefore, $f^{*}$ increases with $a$, and $V_{1}-V_{2}$ decreases with $a$.

\subsection{Proof of Proposition 4}

Proposition 3 implies that the gain from a good reputation, $V_{1}-V_{2}$, increases with $n$ and $\rho$,

and it decreases with $\pi_{0}$. Then, Eq. (18) implies that $\theta^{*}$ (weakly) decreases with $n$ and $\rho$, and it (weakly) increases with $\pi_{0}$.

\subsection{Proof of Proposition 6}

First, taking as given the tech-savvy and old-fogey advisors' reporting strategies, we verify the optimality of the smart investors' investment rule based on the realization of $s_{1}$.

1. $s_{1} \in(a, 1]$. This signal must be from a tech-savvy advisor, and the investment project's payoff $f=s_{1} \geq a \geq I$. Therefore, it is optimal for the smart investor to invest in the project. 
2. $s_{1} \in\left[f^{*}, a\right]$. This signal could be from a tech-savvy or an old-fogey. Given the prior probability $\pi$ that the advisor is tech-savvy, the updated probability is $\hat{\pi}=\frac{\pi}{\pi+(1-\pi) / a}$. Accordingly, the expected project payoff is

$$
E\left\{f \mid s_{1} \in\left[f^{*}, a\right]\right\}=\hat{\pi} s_{1}+(1-\hat{\pi}) s_{1} / a=s_{1} / b(\pi)=\frac{2 s_{1}}{f^{*}+d I} I>I .
$$

Hence the smart investor invests.

3. $s_{1} \in\left(d I, f^{*}\right)$. Since neither tech-savvies nor old-fogies report signals in this range in equilibrium, we need to specify a certain off-equilibrium belief for the investor in order to derive her investment decision. We assume that after receiving a signal in $\left(d I, f^{*}\right)$, the investor believes that the signal could be from either a tech-savvy or an old-fogey with a belief between $s_{1}$ and $f^{*}$. We further assume that the smart investor views the belief of each type of advisor to be uniformly distributed on $\left(s_{1}, f^{*}\right)$. Under these assumptions, the smart investor's updated expectation of the project payoff is

$$
\begin{aligned}
E\left[f \mid s_{1} \in\left(d I, f^{*}\right)\right] & =[\hat{\pi}+(1-\hat{\pi}) / a] \frac{\left(s_{1}+f^{*}\right)}{2} \\
& >[\hat{\pi}+(1-\hat{\pi}) / a] \frac{\left(d I+f^{*}\right)}{2} \\
& =[\hat{\pi}+(1-\hat{\pi}) / a] b(\pi) I \\
& =I .
\end{aligned}
$$

Consequently, the smart investor would choose to invest.

4. $s_{1}=d I$. Such a signal could be from either a tech-savvy or an old-fogey advisor with a belief between $d I$ and $f^{*}$. Given the prior probability $\pi$ that the advisor is tech-savvy, the smart investor's updated probability is $\hat{\pi}$. Then since advisors' beliefs are uniformly distributed, the smart investor's expectation of the project payoff is

$$
\begin{aligned}
E\left[f \mid s_{1}=d I\right] & =[\hat{\pi}+(1-\hat{\pi}) / a] \frac{\left(d I+f^{*}\right)}{2} \\
& =[\hat{\pi}+(1-\hat{\pi}) / a] b(\pi) I \\
& =I .
\end{aligned}
$$

Hence, the investor is indifferent between investing and not investing. 
5. $s_{1} \in[0, d I)$. Such a signal could be a truthful signal from either a tech-savvy or an old-fogey. The smart investor's expectation of the project payoff is

$$
\begin{aligned}
E\left[f \mid s_{1}\right] & =[\hat{\pi}+(1-\hat{\pi}) / a] s_{1} \\
& <[\hat{\pi}+(1-\hat{\pi}) / a] d I \\
& <[\hat{\pi}+(1-\hat{\pi}) / a] b(\pi) I \\
& =I .
\end{aligned}
$$

Accordingly, the investor chooses not to invest.

Next, taking the smart investor's investment strategy as given, we derive the optimal reporting strategies for both the tech-savvy and old-fogey advisors. Both types of advisors want to maximize their advisees' investment profits and simultaneously minimize their dishonesty costs. Given this common objective, tech-savvy and old-fogey advisors have the same optimal reporting strategy. Therefore, in the proof below, we do not differentiate them. We denote $\hat{f}$ as a given advisor's belief about the project fundamental. Based on the realization of $\hat{f}$, we have the following cases.

1. $\hat{f}>I$. The advisor will truthfully report her belief, because it is optimal to invest in the project, and all investors will do so after receiving a truthful signal.

2. $\hat{f} \in\left[f^{*}, I\right)$. The advisor believes that it is inefficient to invest in the project. If she truthfully reports her belief in the signal, a naive advisee will take the signal at face value and will choose not to invest. However, a smart advisee cannot distinguish whether the signal is from a tech-savvy or old-fogey advisor and will choose to invest according to his investment strategy. The advisor can prevent the inefficient investment by her smart advisees by deflating the signal to $d I$. In doing so, the advisor has to incur a dishonesty cost of

$$
n c(\hat{f}-d I)^{2} \geq n c\left(f^{*}-d I\right)^{2}=n \rho\left(I-f^{*}\right)>n \rho(I-\hat{f})
$$

where the last expression equals the total investment losses that would be incurred by her smart advisees if the advisor reports truthfully. Since the dishonesty cost outweighs 
the avoided investment losses, it is not optimal for the advisor to deflate her signal to $d I$. It also is not optimal to deflate her signal to a level higher than $d I$, since a smart advisee still would invest after observing such a signal. Hence, the advisor will truthfully report her belief.

3. $\hat{f} \in\left(d I, f^{*}\right)$. Similar to the previous case, the advisor believes that it is inefficient to invest in the project and faces the dilemma that her smart advisees would choose to invest after observing a truthful signal from her. To avoid this outcome, it now is optimal for the advisor to deflate her signal to $d I$, since her dishonesty cost is smaller than her smart advisees' potential investment losses:

$$
n c(\hat{f}-d I)^{2}<n c\left(f^{*}-d I\right)^{2}=n \rho\left(I-f^{*}\right)<n \rho(I-\hat{f}) .
$$

Again, note that the advisor will not deflate her signal to a level higher than $d I$ since her smart advisees still would choose to invest after receiving such a signal. Hence, it is optimal for the advisor to deflate her signal to $d I$.

4. $\hat{f} \in[0, d I]$. The advisor will truthfully report her belief, since the advisor regards the project as inferior, and all her advisees will avoid the project after receiving a truthful signal.

\subsection{Proof of Proposition 8}

Taking the advisors' reporting strategies as given, it is straightforward to verify the optimality of the smart investors' learning rule. Accordingly, we will focus on the verifying the optimality of an individual advisor's reporting strategy, taking the smart investors' learning rule and other advisors' reporting strategies as given.

First, we verify the optimality of a tech-savvy advisor's reporting strategy. Depending on the realization of her belief $\hat{\theta}^{T S}$, which is equal to $\theta$, we have the following cases.

1. $\hat{\theta}^{T S} \in\left[\theta^{*}, 1\right]$. The advisor knows that other tech-savvy advisors share her belief and will report signals equal to $a \hat{\theta}^{T S}+z$, and that old-fogey advisors will report signals equal to their belief, $a \hat{\theta}^{T S}$. The advisor can choose to inflate her signal to $a \hat{\theta}^{T S}+z$, just like other tech-savvies, and thus obtain a perfect reputation among smart investors. 
The investor also could truthfully report her belief or inflate her signal to a level lower than $a \hat{\theta}^{T S}+z$. (Note that there are no incentives for the advisor to deflate her signal.) Since these alternative signals do not appear in equilibrium, we need to specify an offequilibrium belief for smart investors in order to evaluate the advisor's optimal choice. We assume that if smart investors receive a signal in the region $\left[\hat{\theta}^{T S}, a \hat{\theta}^{T S}+z\right)$, they believe the signal could be from either tech-savvies or old-fogies, and therefore assign the sender the probability $\hat{\pi}=\frac{\pi_{0}}{\pi_{0}+\left(1-\pi_{0}\right) / a}$ of being tech-savvy. Given the investors' learning rule, the feasible choices for the advisor are to truthfully report her belief or to inflate the signal to $a \hat{\theta}^{T S}+z$, which generate reputations of $\hat{\pi}$ and 1 , respectively. The benefit of inflating the signal is $K^{T S}(\hat{\pi})-K^{T S}(1)=K^{T S}(\hat{\pi})$. The dishonesty cost of inflating the signal is

$$
c\left(a \hat{\theta}^{T S}+z-\hat{\theta}^{T S}\right)^{2}=c\left[z-(1-a) \hat{\theta}^{T S}\right]^{2} .
$$

When $\hat{\theta}^{T S}>\theta^{*}$, the inequality conditions in (34) imply that the dishonesty cost is less than $K^{T S}(\hat{\pi})$. Thus, the advisor's optimal strategy is to inflate the signal to $a \hat{\theta}^{T S}+z$.

2. $\hat{\theta}^{T S} \in\left[0, \theta^{*}\right)$. In this region, tech-savvy and old-fogey advisors' signals are pooled at the same level $\hat{\theta}^{T S}$. To verify the optimality of a tech-savvy advisor's strategy, we assume that if an advisor sends a signal above or equal to $\hat{\theta}^{T S}$, smart investors assign her a probability $\hat{\pi}$ of being tech-savvy; and if the advisor sends a signal below $\hat{\theta}^{T S}$, smart investors assign her a probability zero of being tech-savvy. It then directly follows from these assumptions that a tech-savvy advisor's optimal choice is to truthfully report her belief.

Next, we verify the optimality of an old-fogey advisor's reporting strategy. Depending upon the realization of the advisor's belief $\hat{\theta}^{O F}$, which is equal to $a \theta$, we have the following cases.

1. $\hat{\theta}^{O F} \in\left[a \theta^{*}, a\right]$. The advisor knows that other old-fogey advisors will report their belief $\hat{\theta}^{O F}$, while tech-savvy advisors will report $\hat{\theta}^{O F}+z$. We need to show that the advisor's optimal choice is to truthfully report her belief and thus be identified as an old-fogey. She could choose to inflate her signal to $\hat{\theta}^{O F}+z$ and thus be identified as tech-savvy. 
The dishonesty cost that she would incur is $c z^{2}$, while the benefit is $K^{O F}(0)$, which is exactly $c z^{2}$ by construction of $z$ in Proposition 8 . Hence, the advisor is indifferent between truthfully reporting her belief or inflating the signal to $\hat{\theta}^{O F}+z$. The advisor also could inflate her signal to a level in $\left[\hat{\theta}^{O F} / a, \hat{\theta}^{O F}+z\right)$. In equilibrium, no one actually sends a signal in this region. Given our earlier assumption about smart investors' off-equilibrium that they assign the sender a probability $\hat{\pi}$ of being tech-savvy upon receiving a signal in this region, the advisor would only inflate the signal to $\hat{\theta}^{O F} / a$, the minimum level needed to obtain the partial reputation $\hat{\pi}$ as a tech-savvy. The dishonesty cost incurred is

$$
c\left(\hat{\theta}^{O F} / a-\hat{\theta}^{O F}\right)^{2}=c \frac{(1-a)^{2}}{a^{2}} \theta^{\hat{O F}^{2}} \geq K^{O F}(0)-K^{O F}(\hat{\pi}), \quad \forall \hat{\theta}^{O F}>\theta^{*} .
$$

Since $K^{O F}(0)-K^{O F}(\hat{\pi})$ is the benefit of inflating the signal, it is not optimal for the advisor to do so when her belief is above $\theta^{*}$. Also note that the advisor would never choose to inflate her signal to a level lower than $\hat{\theta}^{O F} / a$, because a tech-savvy advisor would never send out a signal in this region. Therefore, truthfully reporting the belief $\hat{\theta}^{O F}$ is an optimal choice.

2. $\hat{\theta}^{O F} \in\left[0, a \theta^{*}\right)$. The old-fogey advisor has two feasible choices. She can either obtain a reputation $\hat{\pi}$ by inflating her signal to $\hat{\theta}^{O F} / a$, or she can identify herself as an old-fogey by reporting her true belief $\hat{\theta}^{O F}$. Since the cost of inflating the signal

$$
c\left(\hat{\theta}^{O F} / a-\hat{\theta}^{O F}\right)^{2}=c \frac{(1-a)^{2}}{a^{2}} \hat{\theta}^{O F^{2}} \leq K^{O F}(0)-K^{O F}(\hat{\pi}), \quad \forall \hat{\theta}^{O F} \leq \theta^{*},
$$

the advisor's optimal choice is to inflate the signal.

\subsection{Proof of Theorem 3}

We begin by taking as given the smart investor's learning rule and verifying the optimality of a tech-savvy's reporting strategy, according to the following cases:

- First, suppose that $\theta \in(a, b)$. In this case, reporting the truth reveals the tech-savvy's type since neither an old-fogey nor a dreamer would ever send such a signal. The techsavvy thus can achieve a perfect reputation while incurring no dishonesty cost, it is optimal for him to tell the truth when $\theta \in(a, b)$. 
- Now, suppose that $\theta \in\left[\theta_{1}^{*}, a\right]$. In this case, the tech-savvy does not need to be worried about being identified as a dreamer since a dreamer will never report a signal in this region. However, an old-fogey might. If $\theta$ is below $a$, the tech-savvy can distinguish himself from an old-fogey by inflating his signal to $a$, at a dishonesty cost of $c(\theta-a)^{2}$. Note that a tech-savvy would never partially inflate his report to a level below $a$, since it would hurt his reputation given the smart investor's learning rule. Since the dishonesty cost increases quadratically with the degree of report inflation, as the fundamental value $\theta$ decreases, the cost of inflating the report increases. When $\theta$ drops below a threshold level given by $\theta_{1}^{*}$, the dishonesty cost becomes too high relative to the gain from signaling that one is a tech-savvy for sure. $\theta_{1}^{*}$ is exactly determined by Eq. (43).

- Then, suppose that the fundamental value $\theta$ is below $\theta_{1}^{*}$. In this case, as we have argued above, it is too costly for the tech-savvy to signal his type by inflating his message to a. We also observe that partially inflating the signal would not improve the advisor's reputation at all. Hence, the advisor chooses to send a truthful signal.

- Next, suppose that $\theta \in\left[b, \theta_{2}^{*}\right]$. In this case, the tech-savvy does not need to be worried about being identified as an old-fogey since an old-fogey will never report a signal in this region. However, a dreamer might. If $\theta$ is above $b$, the tech-savvy can distinguish himself from a dreamer by deflating his signal to $b$, at a dishonesty cost of $c(\theta-b)^{2}$. Note that a tech-savvy would never partially deflate his report to a level above $b$, since it would hurt his reputation given the smart investor's learning rule. Since the dishonesty cost increases quadratically with the degree of report deflation, as the fundamental value $\theta$ increases, the cost of deflating the report increases. When $\theta$ rises above a threshold level given by $\theta_{2}^{*}$, the dishonesty cost becomes too high relative to the gain from signaling that one is a tech-savvy for sure. $\theta_{2}^{*}$ is exactly determined by Eq. (44).

- Finally, suppose that the fundamental value $\theta$ is above $\theta_{2}^{*}$. In this case, as we have argued above, it is too costly for the tech-savvy to signal his type by deflating his message to $b$. We also observe that partially deflating the signal would not improve the advisor's reputation at all. Hence, the advisor chooses to send a truthful signal. 
Next, we verify the optimality of the smart investor's inference rule, given the tech-savvy's reporting strategy.

- If $s_{0} \in[a, b]$, the signal must come from a tech-savvy, since neither old-fogies nor dreamers would report such a signal.

- If $s_{0} \in\left(\theta_{1}^{*}, a\right)$, the signal must come from an old-fogey, since neither tech-savvies nor dreamers would report signals in this region.

- If $s_{0} \leq \theta_{1}^{*}$, the signal could come from either a tech-savvy or an old-fogey, and the probability it is from a tech-savvy is given by Bayes Theorem:

$$
\begin{aligned}
\operatorname{Pr}\left[\text { tech-savvy } \mid s_{0}\right] & =\frac{\lambda\left(s_{0} \mid \text { tech-savvy }\right) \pi_{T S}}{\lambda\left(s_{0} \mid \text { tech-savvy }\right) \pi_{T S}+\lambda\left(s_{0} \mid \text { old-fogey }\right) \pi_{O F}} \\
& =\frac{\pi_{T S}}{\pi_{T S}+\pi_{O F} / a} .
\end{aligned}
$$

Consequently, the probability that the signal comes from an old-fogey is $\frac{\pi_{O F} / a}{\pi_{T S}+\pi_{O F} / a}$.

- If $s_{0} \in\left(b, \theta_{2}^{*}\right)$, the signal must come from a dreamer, since neither tech-savvies nor old-fogies would report signals in this region.

- If $s_{0} \geq \theta_{2}^{*}$, the signal could come from either a tech-savvy or a dreamer, and the probability it is from a tech-savvy is given by Bayes Theorem:

$$
\begin{aligned}
\operatorname{Pr}\left[\text { tech-savvy } \mid s_{0}\right] & =\frac{\lambda\left(s_{0} \mid \text { tech-savvy }\right) \pi_{T S}}{\lambda\left(s_{0} \mid \text { tech-savvy }\right) \pi_{T S}+\lambda\left(s_{0} \mid \text { dreamer }\right) \pi_{D R}} \\
& =\frac{\pi_{T S}}{\pi_{T S}+\pi_{D R} /(1-b)} .
\end{aligned}
$$

Consequently, the probability that the signal comes from a dreamer is $\frac{\pi_{D R} /(1-b)}{\pi_{T S}+\pi_{D R} /(1-b)}$.

\subsection{Proof of Proposition 10}

It is direct to see that $\frac{\pi_{T S}}{\pi_{T S}+\pi_{O F} / a}$ decreases with $\pi_{O F}$. Thus, an increase in $\pi_{O F}$ would cause $V_{T S}-V_{O F}\left(\frac{\pi_{T S}}{\pi_{T S}+\pi_{O F} / a}\right)$ to increase since $V_{O F}(\cdot)$ is a monotonically increasing function. Consequently, $\theta_{1}^{*}$ would decrease with $\pi_{O F}$, as implied by Eq. (43). Similarly, we can prove that $\theta_{2}^{*}$ increases with $\pi_{D R}$, using Eq. (44). 


\section{References}

Abreu, D., Brunnermeier, M., 2003. Bubbles and crashes. Econometrica 71, 173-204.

Allen, F., Morris, S., Postlewaite, A., 1993. Finite bubbles with short sale constraints and asymmetric information. Journal of Economic Theory 61, 206-229.

Bernheim, D., 1994. A theory of comformity. Journal of Political Economy 102, 841-877.

Blanchard, O., Watson, M., 1982. Bubbles, rational expectations and financial markets. In: Wachtel, P. (Ed.), Crisis in the Economic and Financial Structure: Bubbles, Bursts, and Shocks. Lexington Press, Lexington, MA.

Chen, J., Hong, H., Stein, J., 2002. Breadth of ownership and stock returns. Journal of Financial Economics 66, 171-205.

Cowen, A., Groysberg, B., Healy, P., 2003. Which types of analyst firms make more optimistic forecasts. Unpublished working paper, Harvard Business School.

DeLong, J. B., Shleifer, A., Summers, L., Waldmann, R., 1990. Noise trader risk in financial markets. Journal of Political Economy 98, 703-38.

DeMarzo, P., Kaniel, R., Kremer, I., 2006. Relative wealth concerns and financial bubbles. Review of Financial Studies, forthcoming.

Diether, K., Malloy, C., Scherbina, A., 2002. Differences of opinion and the cross section of stock returns. Journal of Finance 52, 2113-2141.

Fudenberg, D., Tirole, J., 1991. Game Theory. MIT Press, Cambridge, MA.

Gerstner, L., 2002. Who Says Elephants Can'T Dance?: Leading A Great Enterprise Through Dramatic Change. Harper Collins, New York, NY.

Greenwood, R., Nagel, S., 2006. Inexperienced investors and bubbles. Unpublished working paper, Harvard Business School.

Grossman, S., Stiglitz, J., 1980. On the impossibility of informationally efficient markets. American Economic Review 70, 393-408.

Groysberg, B., Healy, P., Chapman, C., Gui, Y., 2005. Do buy-side analysts out-perform the sell-side? Unpublished working paper, Harvard Business School.

Harrison, J. M., Kreps, D., 1978. Speculative investor behavior in a stock market with heterogeneous expectations. Quarterly Journal of Economics 92, 323-36.

Hirshleifer, D., Teoh, S. H., 2003. Limited attention, information disclosure, and financial reporting. Journal of Accounting and Economics 36, 337-386.

Holmstrom, B., 1999, Managerial incentive problems: A dynamic perspective. Review of Economic Studies 66, 169-182.

Holmstrom, B., Ricart i Costa, J., 1986. Managerial incentives and capital management. Quarterly Journal of Economics 101, 835-860. 
Hong, H., Kubik, J., 2003. Analyzing the analysts: Career concerns and biased earnings forecasts. Journal of Finance 58, 313-351.

Kreps, D., 1990. A Course in Microeconomic Theory. Princeton University Press, Princeton, NJ.

Lamont, O., Thaler, R., 2003. Can the market add and subtract? Mispricing in tech stock carve-outs. Journal of Political Economy 111, 227-268.

Lin, H., McNichols, M., 1998. Underwriting relationships, analysts' earnings forecasts and investment recommendations. Journal of Accounting and Economics 25, 101-127.

Malkiel, B., 2003. A Random Walk Down Wall Street. W.W. Norton and Company, New York, NY.

Malmenier, U., Shantikumar, D., 2004. Are investors naive about incentives? Journal of Financial Economics, forthcoming.

Michaely, R., Womack, K., 1999. Conflict of interest and the credibility of underwriter analyst recommendations. Review of Financial Studies 12, 653-686.

Miller, E., 1977. Risk, uncertainty and divergence of opinion. Journal of Finance 32, 1151-1168.

Morris, S., 2001. Political correctness. Journal of Political Economy 109, 231-265.

Nairn, A., 2002. Engines That Move Markets. John Wiley and Sons, Inc., New York, NY.

Ofek, E., Richardson, M., 2003. Dotcom mania: The rise and fall of internet stock prices. Journal of Finance 58, 1113-1137.

Ottaviani, M., Sorensen, P., 2006. Professional advice. Journal of Economic Theory 126, 120142.

Pacelle, M., 2000. Soros' Quantum Fund lost big on tech selloff. Smart Money Magazine, January 6, article available online at SmartMoney.com.

Pastor, L., Veronesi, P., 2006. Technological revolutions and stock prices. Unpublished working paper, University of Chicago.

Scharfstein, D., Stein, J., 1990. Herd behavior and investment. American Economic Review 80, 465-479.

Scheinkman, J., Xiong, W., 2003. Overconfidence and speculative bubbles. Journal of Political Economy 111, 1183-1219.

Shiller, R., 2000. Irrational Exuberance. Broadway Books, New York, NY.

Shleifer, A., Vishny, R., 1997. Limits of arbitrage. Journal of Finance 52, 35-55.

Wolfe, T., 1975. The Painted Word. Farrar, Straus and Giroux, New York, NY. 